\title{
Dynamics of Interannual Variability in Summer Precipitation over East Asia*
}

\author{
YU KOSAKA \\ International Pacific Research Center, School of Ocean and Earth Science and Technology, University of Hawaii at Manoa, \\ Honolulu, Hawaii \\ SHANG-PING XIE \\ Department of Meteorology, and International Pacific Research Center, School of Ocean and Earth Science and Technology, \\ University of Hawaii at Manoa, Honolulu, Hawaii \\ HISASHI NAKAMURA ${ }^{+}$ \\ Department of Earth and Planetary Science, The University of Tokyo, Tokyo, and Research Institute for \\ Global Change, JAMSTEC, Yokohama, Japan
}

(Manuscript received 24 September 2010, in final form 14 February 2011)

\begin{abstract}
The summertime mei-yu-baiu rainband over East Asia displays considerable interannual variability. A singular value decomposition (SVD) analysis for interannual variability reveals that precipitation anomalies over the mei-yu-baiu region are accompanied by in situ anomalies of midtropospheric horizontal temperature advection. Anomalous warm (cool) advection causes increased (decreased) mei-yu-baiu precipitation locally by inducing adiabatic ascent (descent). The anomalous precipitation acts to reinforce the vertical motion, forming a feedback system. By this mechanism, the remotely forced anomalous atmospheric circulation can induce changes in mei-yu-baiu precipitation. The quasi-stationary precipitation anomalies induced by this mechanism are partially offset by transient eddies.

The SVD analysis also reveals the association of mei-yu-baiu precipitation anomalies with several teleconnection patterns, suggesting remote induction mechanisms. The Pacific-Japan (PJ) teleconnection pattern, which is associated with anomalous convection over the tropical western North Pacific, contributes to mei-yu-baiu precipitation variability throughout the boreal summer. The PJ pattern mediates influences of the El Niño-Southern Oscillation in preceding boreal winter on mei-yu-baiu precipitation. In early summer, the leading covariability pattern between precipitation and temperature advection also features the Silk Road pattern - a wave train along the summertime Asian jet—and another wave train pattern to the north along the polar-front jet that often leads to the development of the surface Okhotsk high.
\end{abstract}

\section{Introduction}

In East Asia there is a warm, humid rainy season in summer, called mei-yu in China and baiu in Japan

* International Pacific Research Center Publication Number 771 and School of Ocean and Earth Science and Technology Publication Number 8122.

${ }^{+}$Current affiliation: Research Center for Advanced Science and Technology, The University of Tokyo, Tokyo, Japan.

Corresponding author address: Yu Kosaka, IPRC, SOEST, University of Hawaii, 1680 East-West Rd., Honolulu, HI 96822.

E-mail: ykosaka@hawaii.edu
(Ninomiya and Murakami 1987). Abundant rainfall in the rainy season (June-mid-July; hereafter early summer) sustains agricultural and thus socioeconomic activities in the densely populated region. The mei-yu-baiu rainfall is known to undergo substantial interannual variability. An extremely low amount of rainfall in the early summer season can cause a shortage of water resources, while heavy rainfall leads to floods.

In early summer, a quasi-stationary rainband, hereafter referred to as the mei-yu-baiu rainband, extends zonally from the southern and eastern portions of China to the east of Japan (Fig. 1c). Climatologically, the meiyu-baiu rainband forms in mid-May and gradually advances northward in its western portion between China 
(a) $\bar{P}\left(110^{\circ}-140^{\circ} \mathrm{E}\right)$

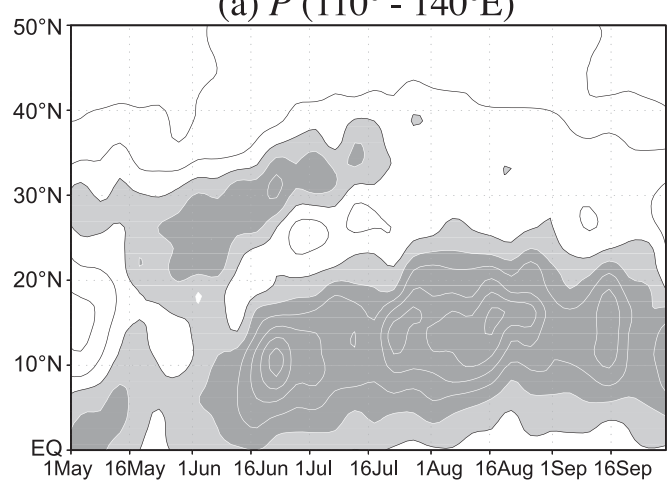

(c) $\bar{P}$ (early summer)

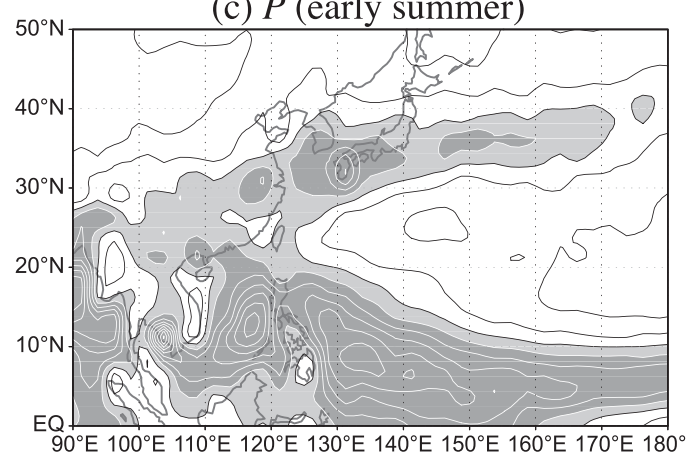

(e) $\bar{q},-\overline{\mathbf{u} \cdot \nabla T}$ (early summer)

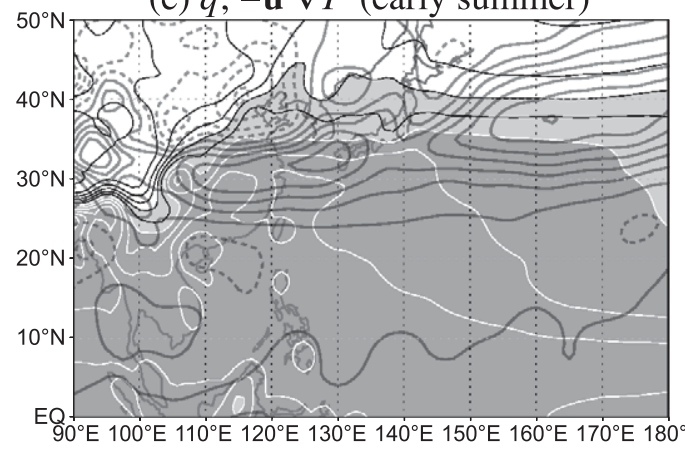

(b) $\bar{P}\left(140^{\circ}-170^{\circ} \mathrm{E}\right)$

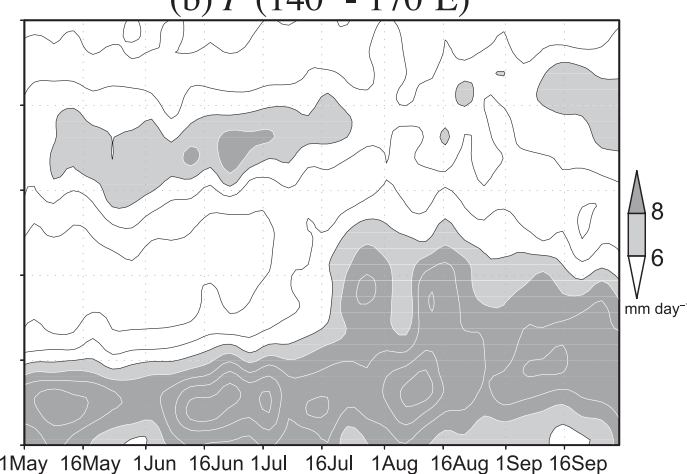

(d) $\bar{P}$ (midsummer)

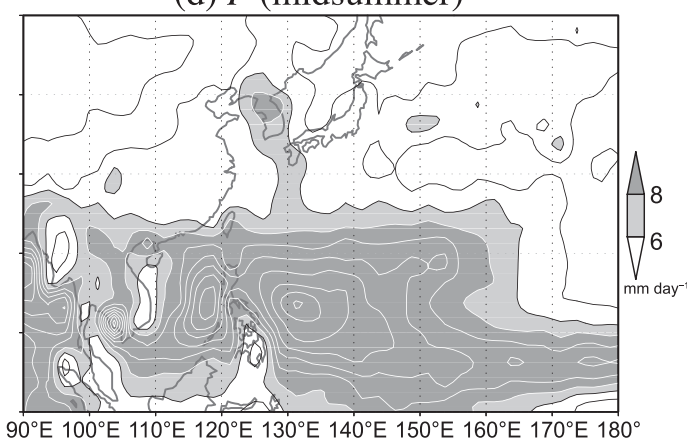

(f) $\bar{q},-\overline{\mathbf{u} \cdot \nabla T}$ (midsummer)

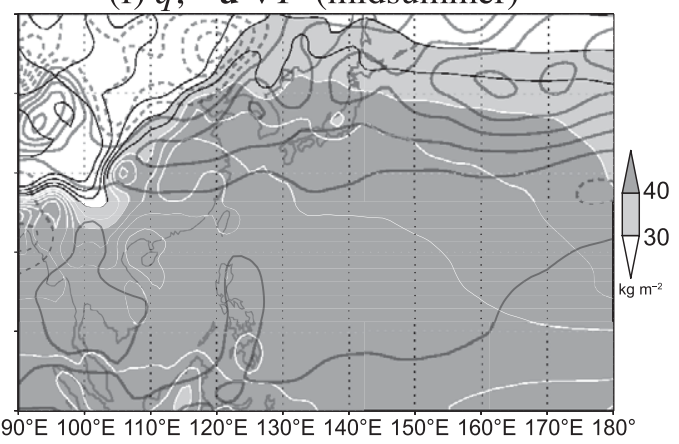

FIG. 1. Time-latitude section of climatological precipitation averaged over (a) $110^{\circ}-140^{\circ} \mathrm{E}$ and (b) $140^{\circ}-170^{\circ} \mathrm{E}$. Horizontal distributions of climatological (c),(d) precipitation and (e),(f) precipitable water (thin white and black contours) and horizontal temperature advection at the 500-hPa level (thick contours, with solid and dashed lines representing warm and cool advection, respectively) for (c),(e) early summer (15 Jun-14 Jul) and (d),(f) midsummer (20 Jul-18 Aug). Contour interval is $2 \mathrm{~mm} \mathrm{day}^{-1}$ in (a)-(d), $5 \mathrm{~kg} \mathrm{~m}^{-2}$ for precipitable water in (e),(f), and $3 \times 10^{-6}$ $\mathrm{K} \mathrm{s}^{-1}$ for temperature advection. Light and dark shading indicates precipitation greater than 6 and $8 \mathrm{~mm} \mathrm{day}^{-1}$, respectively, in (a)-(d) and precipitable water greater than 30 and $40 \mathrm{~kg} \mathrm{~m}^{-2}$, respectively in (e),(f).

and Japan (Fig. 1a), while the poleward migration is less pronounced in the eastern portion east of Japan (Fig. 1b). In the Yangtze River valley region and central and western Japan, the rainy season begins in mid-June. The rainband suddenly weakens in mid- to late July (Figs. 1a,b), marking the arrival of the hottest season (midsummer; Fig. 1d). At the same time, convection intensifies over the tropical ocean $\left(15^{\circ}-20^{\circ} \mathrm{N}\right)$ to the south (Figs. 1a,b; Ueda et al. 1995, 2009). Subsequently, the primary rainfall maximum of the mei-yu-baiu rainband shifts to the Korean Peninsula (Fig. 1d).

Recently, Sampe and Xie (2010, hereafter SX10) proposed a mechanism for the formation of the climatological mei-yu-baiu rainband. They suggest that the midtropospheric westerly jet in the midlatitudes induces adiabatic ascending motion by advecting warm temperature from the Tibetan Plateau toward the North Pacific (Fig. 1e). The adiabatic ascent, together with abundant moisture 
transported by the lower-tropospheric southerlies, sets a favorable condition for precipitation. Diabatic heating associated with the precipitation, in turn, reinforces the ascent locally and downstream. Consequently, the rainband is formed along the westerly jet. Chinese forecasters have been monitoring the $5880-\mathrm{m}$ contour of $500-\mathrm{hPa}$ geopotential height field as an indicator of the mei-yu rainband, based on their empirical knowledge that it tends to be observed along the northern periphery of this contour. This empirical relationship is consistent with the midtropospheric warm advection mechanism proposed by SX10.

Variability of mei-yu-baiu precipitation has received much attention from the climate community. Despite numerous studies on low-frequency variability of mei-yubaiu precipitation, however, dynamical mechanisms for coupled rainfall-circulation variability in the midlatitudes remain poorly understood. The major difficulty has to do with a lack of understanding about how circulation anomalies can lead to rainfall change in the mei-yu-baiu region, even though circulation response to given diabatic heating has been studied extensively. Specifically, many previous studies invoked anomalous moisture flux and its convergence in explaining mei-yu-baiu precipitation anomalies. Such a discussion is, however, no more than confirming consistency in the moisture budget, leaving the causality between the circulation and precipitation anomalies unsolved. In an attempt to resolve this causality issue, we propose to consider midtropospheric circulation anomalies as a cause of mei-yu-baiu rainfall variability, in recognition of the fact that circulation response to deep latent heating is primarily baroclinic with a minimum in the midtroposphere (SX10). Through analysis of observational data, the present study verifies this hypothesis by identifying covariability of midtropospheric circulation and mei-yu-baiu precipitation. Our analysis confirms the warm advection mechanism of SX10 and generalizes it to interannual variability.

On intraseasonal-to-interannual time scales, mei-yubaiu precipitation anomalies are accompanied by largescale anomalous circulation. The Bonin high plays an important role. It is an equivalent barotropic anticyclone forming at the western (eastern) edge of the North Pacific subtropical anticyclone in the lower troposphere (the upper-tropospheric Tibetan or South Asian high). Anomalous intensification (weakening) of the Bonin high is often concomitant with a northward (southward) displacement and a weakening (intensification) of the mei-yu-baiu rainband, suggesting the applicability of the warm advection mechanism to long-term variability of the rainband. The strength of the Bonin high tends to vary concomitantly also with convective activity over the tropical western North Pacific (WNP) around and east of the Philippines via a teleconnection called the
Pacific-Japan (PJ) pattern (Nitta 1987; Huang and Sun 1992; Kosaka and Nakamura 2006, 2010). Another teleconnection called the Silk Road pattern, a wave train pattern along the summertime Asian jet centered near $40^{\circ} \mathrm{N}$, also influences the strength of the Bonin high (Enomoto et al. 2003; Enomoto 2004; Kosaka et al. 2009). Interannual variability of mei-yu-baiu precipitation in relation to the El Niño-Southern Oscillation (ENSO) has been investigated in many studies (Tanaka 1997; Wang et al. 2001; Huang et al. 2004; Tomita et al. 2004). They found that mei-yu-baiu rainfall tends to increase (decrease) in summer following an El Niño (La Niña) event in boreal winter. Recently, Xie et al. (2009) proposed the following "Indian Ocean capacitor effect" to explain this lingering effect of ENSO: persistent warm anomalies in the tropical Indian Ocean sea surface temperature (SST) after El Niño [Indian Ocean basin mode (IOBM)] excite a warm tropospheric Kelvin wave, which induces surface Ekman divergence over the tropical WNP, triggers the PJ pattern, and eventually influences the mei-yu-baiu rainband. The present study investigates the circulationprecipitation covariability over summer East Asia in relation to atmospheric teleconnection patterns and major modes of SST variability including ENSO.

The rest of the paper is organized as follows. Section 2 describes the data. Section 3 briefly reviews climatological features of the mei-yu-baiu rainband and the warm advection mechanism by SX10. Sections 4 and 5 discuss dynamical features associated with mei-yu-baiu precipitation anomalies in early summer and midsummer, respectively, based on singular value decomposition (SVD) analyses. Section 6 further investigates the covariability of precipitation and circulation anomalies independently of the SVD method. Section 7 is a summary and provides additional discussion.

\section{Data}

The present study uses 6-hourly data of the Japanese 25-yr reanalysis (JRA-25) of the global atmosphere (Onogi et al. 2007) and pentad-mean data of the Climate Prediction Center (CPC) Merged Analysis of Precipitation (CMAP; Xie and Arkin 1997), both given on a $2.5^{\circ} \times 2.5^{\circ}$ horizontal grid. We define early summer (the East Asian rainy season) as a 30-day period from 15 June to 14 July (Fig. 1c). The withdrawal of the mei-yubaiu rainband brings the hottest midsummer season, which is defined in the present study as another 30-day period from 20 July to 18 August (Fig. 1d). Since the transition date from early summer to midsummer varies from one year to another (Suzuki and Hoskins 2009), averaging over these periods may include signals of the earlier or delayed transition. After averaging temperature 
and horizontal wind of the JRA-25 for each of these periods, we calculated horizontal temperature advection $(-\mathbf{u} \cdot \nabla T)$ for every year, where $\mathbf{u}$ is horizontal wind, $T$ is temperature, and $\nabla$ is the horizontal gradient operator. The monthly Met Office Hadley Centre Sea Ice and Sea Surface Temperature data (HadISST; Rayner et al. 2003), given on a $1^{\circ} \times 1^{\circ}$ grid, are also used. Climatologicalmean and anomaly fields, including the horizontal temperature advection, are obtained as a 29-yr mean from 1979 to 2007 and departure from it, respectively. Removing the 29-yr linear trend from the anomaly fields did not yield any qualitative differences in our analyses.

To extract large-scale circulation features, horizontal smoothing is applied to the vorticity fields by multiplying a coefficient $\exp \left\{-K[n(n+1)]^{2}\right\}$ (Hoskins 1980), where $n$ is the total wavenumber, and the constant $K$ is set in such a way that the harmonic component of $n=24$ is reduced by $50 \%$. Hereafter, vorticity refers to the horizontally smoothed field unless otherwise specified. Diabatic heating $Q_{1}$ has been derived as a residual of thermodynamic equation with 6-hourly JRA-25 data.

\section{Climatological features}

The climatological mei-yu-baiu rainband is situated near $30^{\circ} \mathrm{N}$ over eastern China and extends northeastward to southern Japan and farther to its east in early summer (Fig. 1c). The position of the rainband corresponds well to that of the midtropospheric warm advection (Fig. 1e; SX10). In midsummer, the intensity of the rainband becomes much weaker, and the primary rainy region shifts to the Korean Peninsula (Fig. 1d). This precipitation center coincides with a local maximum of the midtropospheric warm advection (Fig. 1f). Yet, the induction of precipitation by vertical motion is effective only if there is sufficient moisture. Climatologically, moisture is transported into the midlatitude WNP by lower-tropospheric tropical/subtropical southerlies, enabling the formation of the mei-yu-baiu rainband (Figs. 1e,f). Mean moisture is small north of $40^{\circ} \mathrm{N}$ over the WNP (Figs. 1e,f). Because of a slight southwestnortheast tilt of the midtropospheric warm advection, the lack of abundant moisture in higher latitudes confines the mei-yu-baiu rainband to the southwestern portion of the warm advection region (Fig. 1c; SX10). The weakening of the mei-yu-baiu rainband in midsummer (Fig. 1d) may be attributable, at least in part, to the reduction of the warm advection and its poleward displacement out of the region of abundant moisture owing to a seasonal migration of the Asian jet (Fig. 1f).

In the tropics to the south, heavy precipitation is observed over the South China Sea and east of the Philippines in early summer (Fig. 1c). This region of heavy precipitation expands northeastward in midsummer (Fig. 1d; Ueda et al. 1995, 2009). In contrast to the meiyu-baiu region, both midtropospheric temperature gradient and thermal advection are weak in the tropics and subtropics, where precipitation is controlled primarily by local convective instability.

Interannual variance of precipitation in early summer is concentrated in a zonally elongated region along the climatological rainband (Figs. 2a,c). Despite the marked reduction in the climatological mei-yu-baiu precipitation into midsummer, the zonal band of interannual variance maxima is still evident from eastern China to east of Japan almost at the same latitudes as those in early summer, with a comparable magnitude of variance (Figs. 2a,b,d). In the tropics, the region of large interannual variance of precipitation shifts northward from about $13^{\circ} \mathrm{N}$ in early summer (Fig. 2c) to about $18^{\circ} \mathrm{N}$ in midsummer (Fig. 2d), following the climatological northward expansion of the region of heavy precipitation (Figs. 1c,d).

\section{Interannual variability in early summer}

\section{a. Interannual variability}

An SVD analysis is applied to precipitation and 500$\mathrm{hPa}$ horizontal advection of temperature for the early summer season. The particular choice of the $500-\mathrm{hPa}$ level is based on the following argument by SX10: observed circulation anomalies include the response to mei-yu-baiu diabatic heating, complicating the causality between the circulation and precipitation anomalies. As shown later, anomalous diabatic heating is deep in the mei-yu-baiu region. Since the circulation response to the deep latent heating is projected mostly onto the first baroclinic mode (see a linear baroclinic model experiment in the appendix of SX10), focusing on midtropospheric circulation considerably reduces that complication in interpreting the causality.

On the basis of Fig. 2c, the SVD analysis has been applied to the two variables over a domain of $\left(20^{\circ}-45^{\circ} \mathrm{N}\right.$, $\left.110^{\circ}-170^{\circ} \mathrm{E}\right)$. The fractions of the squared covariance explained by the leading and second SVD modes (SVD1 and SVD2) are $47.2 \%$ and $18.4 \%$, respectively. The leading empirical orthogonal function (EOF) obtained for precipitation over the same domain yields almost the same pattern as extracted in SVD1, with their pattern correlation coefficient of 0.90 . The corresponding relationship also holds between SVD2 and the second EOF for precipitation (their pattern correlation coefficient: 0.84). These results indicate that our SVD analysis extracts the leading patterns of interannual variability in mei-yu-baiu precipitation. 
(a) $\sigma(P)\left(110^{\circ}-140^{\circ} \mathrm{E}\right)$

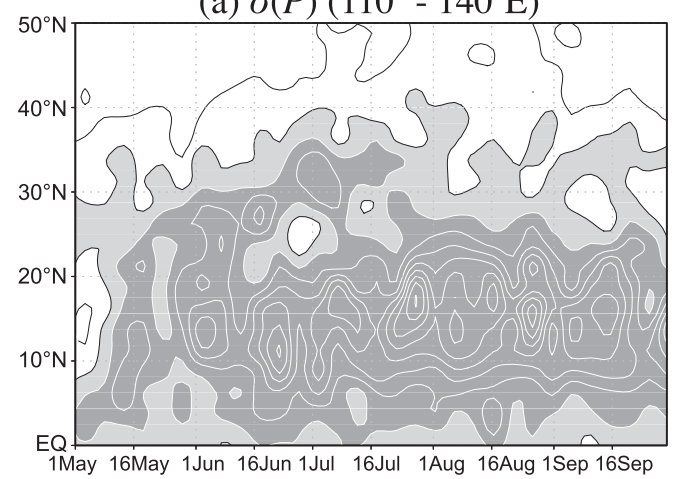

(c) $\sigma(P)$ (early summer)

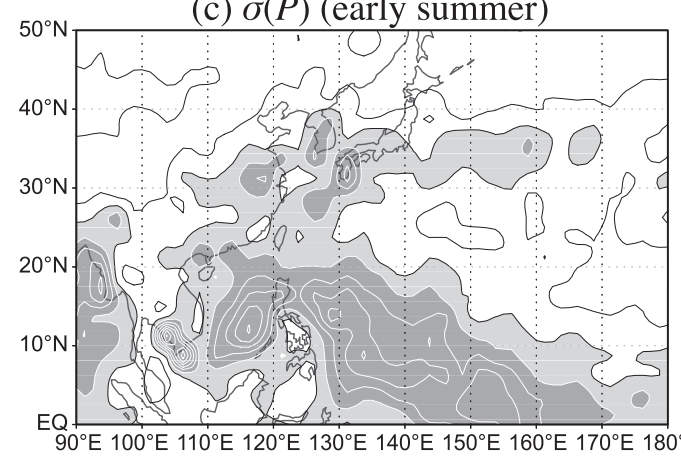

(b) $\sigma(P)\left(140^{\circ}-170^{\circ} \mathrm{E}\right)$

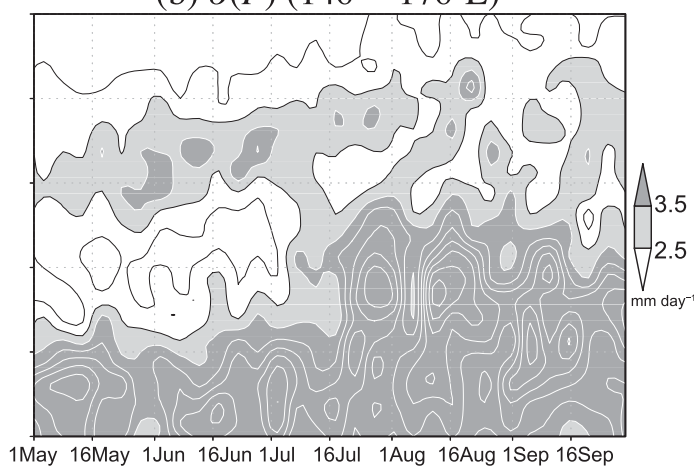

(d) $\sigma(P)$ (midsummer)

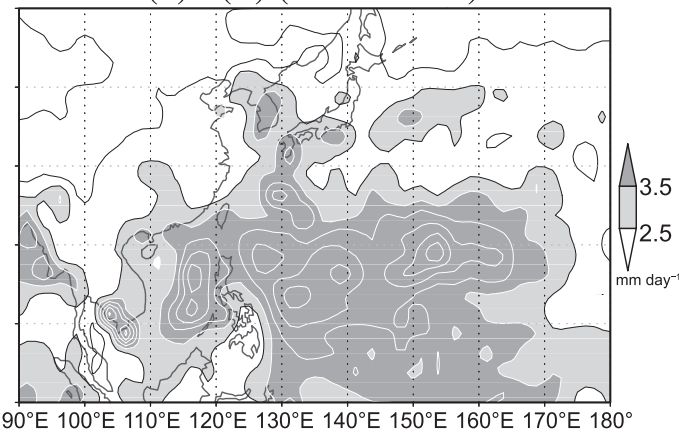

FIG. 2. As in Figs. 1a-d, but for interannual standard deviation of precipitation. Contour interval is $1(0.5,1.5,2.5, \ldots) \mathrm{mm} \mathrm{day}^{-1}$. Light and dark shading indicates values larger than 2.5 and $3.5 \mathrm{~mm} \mathrm{day}^{-1}$, respectively.

Figure 3 shows anomaly patterns of precipitation and horizontal temperature advection extracted in SVD1 as the homogeneous and heterogeneous regression maps onto the temporal coefficients corresponding to SVD1. The homogeneous and heterogeneous regression maps display remarkable resemblance to each other (Fig. 3a versus Fig. 3b and Fig. 3c versus Fig. 3d), indicating a strong coupling between the precipitation and thermal advection anomalies. In fact, the correlation between the two temporal coefficients is very high, which also holds for SVD2 (Table 1). For the rest of paper, we therefore focus on the regression maps based on the temporal coefficient of precipitation, except for precipitation that will be regressed onto the temperature advection time series.

The precipitation anomaly field, in the particular polarity shown in Figs. 3a and 3b, is characterized by a band of positive anomalies extending from the south of the Yangtze River valley eastward/northeastward along the southern coast of Japan and to its east. Significant reductions of precipitation are observed to the north and south, one centered at the Korean Peninsula and the other distributed over the South China Sea and east of the Philippines (Figs. 3a,b). The pattern represents a southward migration of the climatological mei-yu-baiu rainband west of $145^{\circ} \mathrm{E}$ and a local enhancement of mei-yu-baiu precipitation to the east. In contrast, SVD2 represents a local intensification of the mei-yu-baiu precipitation over the Yangtze River valley, East China Sea, and Japan, in the particular polarity shown in Fig. 4a. The precipitation anomaly patterns in SVD1 and SVD2 are similar to those identified through a cluster analysis by Yamaura and Tomita (2011).

Table 1 summarizes correlation statistics of SVD1 and SVD2 with major climate indices. While SVD2 shows significant correlation with none of the indices listed, SVD1 is significantly correlated with the El Niño index in the preceding winter [December-February; hereafter $\mathrm{D}(-1) \mathrm{JF}(0)]$ and the IOBM index, defined as SST anomalies averaged over $20^{\circ} \mathrm{S}-20^{\circ} \mathrm{N}, 40^{\circ}-100^{\circ} \mathrm{E}$, in the concurrent summer [June-August; hereafter JJA(0)]. These correlations are indicative of the Indian Ocean capacitor effect (Xie et al. 2009). ${ }^{1}$

Figure 5 shows meridional sections of vertical $p$ velocity and $Q_{1}$ anomalies averaged over $120^{\circ}-140^{\circ} \mathrm{E}$

\footnotetext{
${ }^{1}$ Years relative to time series associated with SVD modes are indicated with numbers in parentheses hereafter.
} 
(a) $P^{\prime}$ (homogeneous)

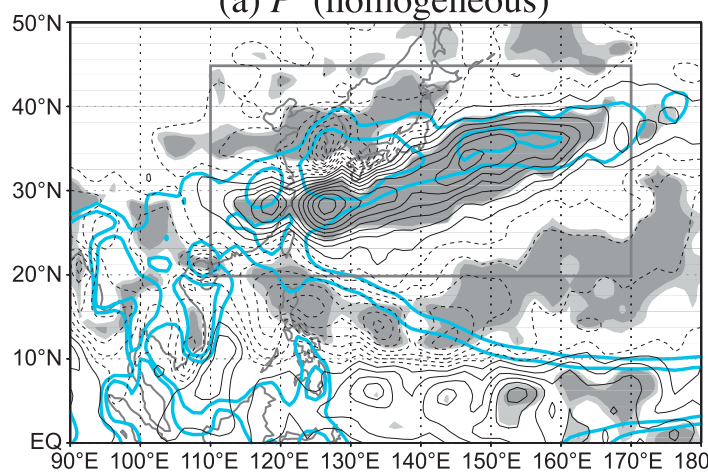

(b) $P^{\prime}$ (heterogeneous)

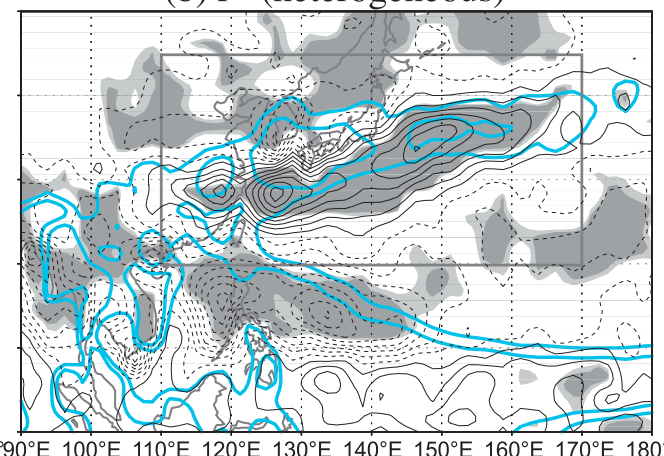

(c) $500 \mathrm{hPa}-(\mathbf{u} \cdot \nabla T)^{\prime}$ (heterogeneous), $\mathbf{u}^{\prime}, \bar{T}$

(d) $500 \mathrm{hPa}-(\mathbf{u} \cdot \nabla T)^{\prime}$ (homogeneous), $\mathbf{u}^{\prime}, \bar{T}$

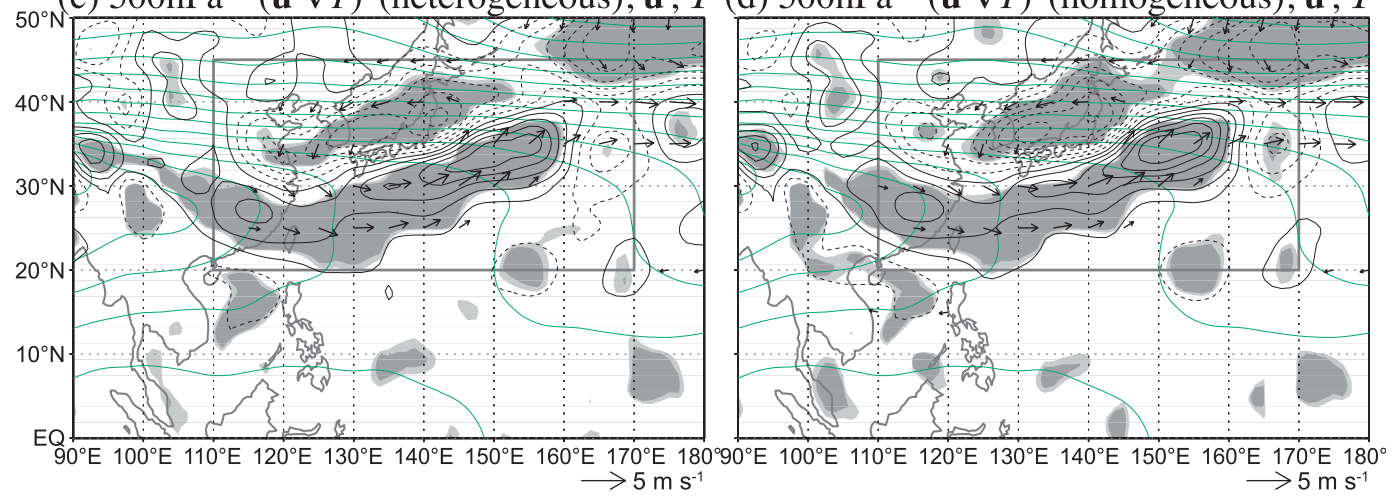

FIG. 3. Anomalies of (a),(b) precipitation and (c),(d) horizontal temperature advection at the 500-hPa level regressed onto temporal coefficients of the leading SVD mode between precipitation and 500-hPa horizontal temperature advection over $20^{\circ}-45^{\circ} \mathrm{N}, 110^{\circ}-170^{\circ} \mathrm{E}$, a region indicated by boxes with thick lines, for early summer ( $15 \mathrm{Jun}-$ $14 \mathrm{Jul}$ ). The temporal coefficient is obtained for (a),(c) precipitation and (b),(d) temperature advection. Contour interval in (a),(b) is $0.4( \pm 0.2, \pm 0.6, \pm 1, \ldots) \mathrm{mm} \mathrm{day}^{-1}$ and in (c),(d) is $1( \pm 0.5, \pm 1.5, \pm 2.5, \ldots) \times 10^{-6} \mathrm{~K} \mathrm{~s}^{-1}$. $\mathrm{Light}^{-}$ and dark shading represent the confidence levels of $90 \%$ and $95 \%$, respectively, based on the $t$ statistic. Light blue contours in (a),(b) indicate climatological-mean precipitation of 6 and $8 \mathrm{~mm} \mathrm{day}^{-1}$. In (c),(d), arrows and green contours indicate regressed horizontal wind anomalies (with the scale at the bottom of each panel) and climatologicalmean temperature (with 1-K interval), respectively, at the 500-hPa level.

associated with SVD1 and SVD2. The anomalous diabatic heating is indeed deep around the mei-yu-baiu rainband $\left(23^{\circ}-45^{\circ} \mathrm{N}\right)$, maximized between the 400 - and 500-hPa levels (Figs. 5b,d). Correspondingly, anomalous vertical motion is strongest in the midtroposphere (Figs. 5a,c). These vertical structures a posteriori justify our choice of the 500-hPa level for horizontal temperature advection.

Additionally, we have repeated the SVD analysis with 700-hPa temperature advection, which is found to yield almost the same patterns and temporal coefficients as those based on 500-hPa advection. Spatial correlations between SVD1s (SVD2s) are 0.95 (0.82) for precipitation and $0.97(0.84)$ and 0.97 (0.81) for the homogeneously regressed temperature advection anomalies at the 500and $700-\mathrm{hPa}$ levels, respectively. Correlations of the temporal coefficients of SVD1s (SVD2s) are 0.97 (0.88) for precipitation and $0.90(0.72)$ for the temperature advection. These high correlations suggest that our SVD analysis is robust, as it is insensitive to the specific choice of midtropospheric pressure level for temperature advection.

\section{b. Dynamical induction of anomalous mei-yu-baiu precipitation}

SVD1 is characterized by dipolar bands of anomalous warm and cool advection in the midtroposphere (Figs. 3c,d). In the particular polarity shown in Fig. 3, the anomalous warm advection over southeastern China, the East China Sea, and along the southern coast of Japan (Figs. 3c,d) are associated with positive anomalies of precipitation (Figs. 3a,b). The anomalous warm advection is primarily due to anomalous wind blowing across the climatological-mean isotherms (Figs. 3c,d). The collocation of the increased precipitation and westerly anomalies is consistent with Ninomiya and Mizuno 
TABLE 1. Correlation coefficients with climate indices of time series obtained for the leading and second SVD modes between precipitation $P$ and $500-\mathrm{hPa}$ temperature advection $(-\mathbf{u} \cdot \nabla T)$ for early summer ( $15 \mathrm{Jun}-14 \mathrm{Jul}$ ) over $20^{\circ}-45^{\circ} \mathrm{N}, 110^{\circ}-170^{\circ} \mathrm{E}$, and midsummer (20 Jul-18 Aug) over $30^{\circ}-50^{\circ} \mathrm{N}, 110^{\circ}-170^{\circ} \mathrm{E}$. Climate indices are SST anomalies averaged over the Niño-3.4 $\left(5^{\circ} \mathrm{S}-5^{\circ} \mathrm{N}, 170^{\circ}-120^{\circ} \mathrm{W}\right) \mathrm{region}$, the tropical Indian Ocean $\left(20^{\circ} \mathrm{S}-20^{\circ} \mathrm{N}, 40^{\circ}-100^{\circ} \mathrm{E}\right)$ for the IOBM, and the SST difference between the western $\left(10^{\circ} \mathrm{S}-10^{\circ} \mathrm{N}, 50^{\circ}-70^{\circ} \mathrm{E}\right)$ and eastern $\left(10^{\circ} \mathrm{S}-0^{\circ}, 90^{\circ}-110^{\circ} \mathrm{E}\right)$ centers of Indian Ocean dipole (IOD; Saji et al. 1999). Correlation coefficient between precipitation and temperature advection in an SVD mode is shown as $r(P,-\mathbf{u} \cdot \nabla T)$. Values exceeding the $90 \%, 95 \%$, and $99 \%$ confidence level(s) are highlighted in boldface and with asterisks and daggers, respectively, based on a nonparametric bootstrap test.

\begin{tabular}{|c|c|c|c|c|c|c|c|c|}
\hline \multirow{4}{*}{$\begin{array}{l}\text { Climate index } \\
\qquad r(P,-\mathbf{u} \cdot \nabla T)\end{array}$} & \multicolumn{4}{|c|}{ Early summer } & \multicolumn{4}{|c|}{ Midsummer } \\
\hline & \multicolumn{2}{|c|}{ SVD1 } & \multicolumn{2}{|c|}{ SVD2 } & \multicolumn{2}{|c|}{ SVD1 } & \multicolumn{2}{|c|}{ SVD2 } \\
\hline & $P$ & $-\mathbf{u} \cdot \nabla T$ & $P$ & $-\mathbf{u} \cdot \nabla T$ & $P$ & $-\mathbf{u} \cdot \nabla T$ & $P$ & $-\mathbf{u} \cdot \nabla T$ \\
\hline & \multicolumn{2}{|c|}{$0.89^{\dagger}$} & \multicolumn{2}{|c|}{$\mathbf{0 . 8 0}^{\dagger}$} & \multicolumn{2}{|c|}{$0.86^{\dagger}$} & \multicolumn{2}{|c|}{$\mathbf{0 . 7 9}^{\dagger}$} \\
\hline Niño-3.4 [D(-1)JF(0)] & $0.43^{*}$ & 0.35 & -0.25 & -0.17 & $0.43 *$ & $0.41^{*}$ & 0.00 & 0.16 \\
\hline Niño-3.4 [JJA $(0)]$ & 0.15 & 0.16 & 0.08 & 0.27 & 0.09 & 0.15 & -0.04 & 0.00 \\
\hline $\operatorname{IOBM}[\operatorname{JJA}(0)]$ & $0.40 *$ & 0.41 & 0.02 & -0.05 & $\mathbf{0 . 5 9} 9^{\dagger}$ & $0.43^{*}$ & -0.01 & 0.06 \\
\hline $\operatorname{IOD}[\operatorname{JJA}(0)]$ & 0.19 & 0.17 & -0.11 & -0.26 & 0.26 & 0.12 & 0.03 & 0.04 \\
\hline
\end{tabular}

(1987). Figures 3c and 3d also exhibit anomalous cool advection to the north, which is associated with anomalous northeasterlies primarily around the Korean Peninsula, where significant reduction of precipitation is observed (Figs. 3a,b). The cool advection around northern Japan is also due to temperature anomalies advected by the climatological-mean wind (figure not shown).

Early summer SVD2 features significant anomalous warm advection over China, the East China Sea, and Japan and cool advection over northern China and the Yellow Sea (Fig. 4b). Although the warm advection anomaly is rather weak east of Japan (Fig. 4b), the anomalous warm and cool advection, due to anomalous southwesterlies and northeasterlies (Fig. 4b), respectively, is in good correspondence with enhanced and reduced precipitation in those regions (Fig. 4a). The correspondence is, however, less obvious between reduced precipitation and anomalous cool advection southeast of Japan (Fig. 4), where precipitation is weak climatologically (Fig. 1c). Section 4c elucidates a possible cause of this discrepancy.
The overall collocation of precipitation increase (decrease) with midtropospheric warm (cool) advection anomalies represented in SVD1 and SVD2 is consistent with SX10. We suggest that the anomalous temperature advection induces anomalous vertical motion adiabatically, thereby changing precipitation locally. This precipitation induction mechanism, however, requires the availability of sufficient moisture in the mean field. Because of the sharp northward decline of the climatological moisture between $35^{\circ}$ and $40^{\circ} \mathrm{N}$ (Fig. 1e), distinct precipitation anomalies are confined south of $40^{\circ} \mathrm{N}$. In fact, anomalous precipitation in SVD1 is strongest in the southwestern portion of anomalous temperature advection region, which has a southwest-northeast orientation (Figs. 3a,b), even though the temperature advection anomalies are strongest in its eastern portion (Figs. 3c,d). This result is indicative of the importance of moisture availability for the precipitation induction mechanism to be operative.

Anomalous ascent (descent) associated with both SVD1 and SVD2 is collocated in the midlatitudes with (a) $P^{\prime}$ (heterogeneous)

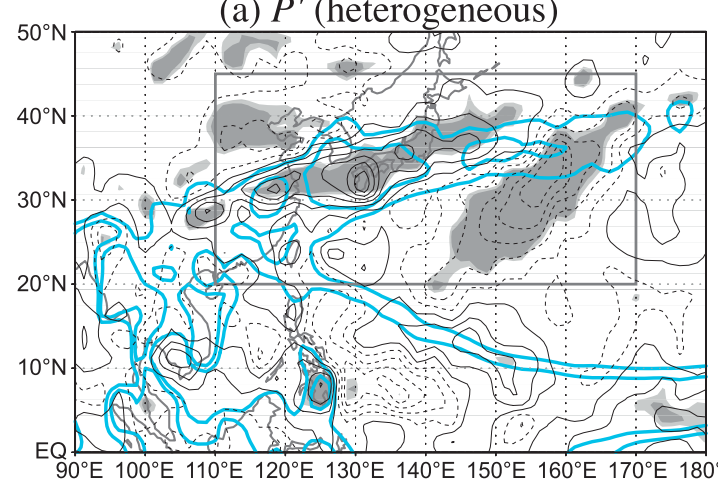

(b) $500 \mathrm{hPa}-(\mathbf{u} \cdot \nabla T)^{\prime}$ (heterogeneous), $\mathbf{u}^{\prime}, \bar{T}$

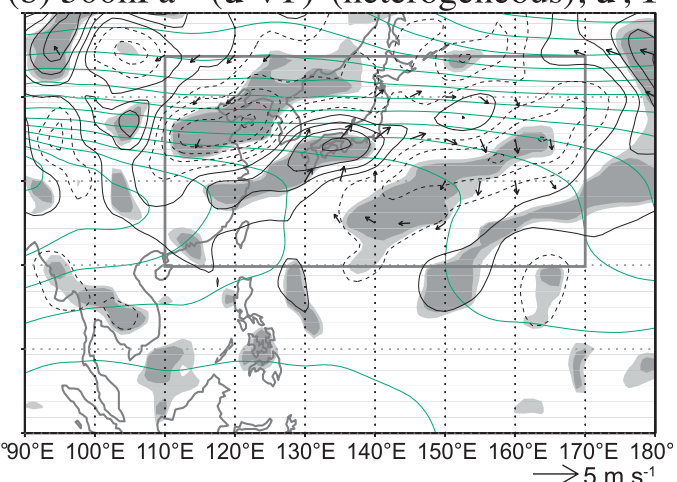

FIG. 4. (a),(b) As in Figs. 3b and 3c, respectively, but for the second SVD mode. 
(a) $120^{\circ}-140^{\circ} \mathrm{E}-\omega^{\prime}(\mathrm{SVD} 1)$

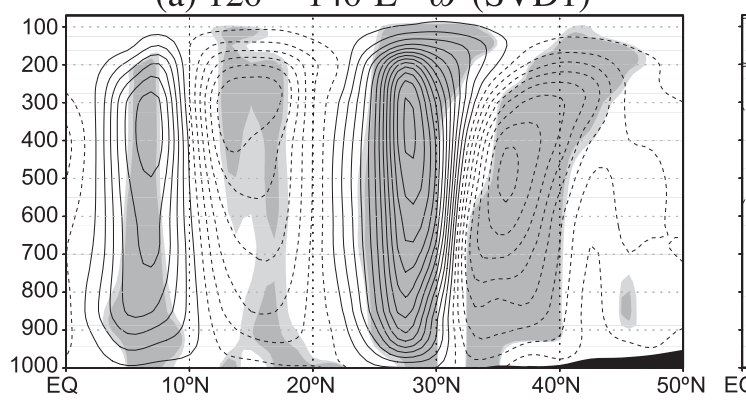

(c) $120^{\circ}-140^{\circ} \mathrm{E}-\omega^{\prime}(\mathrm{SVD} 2)$

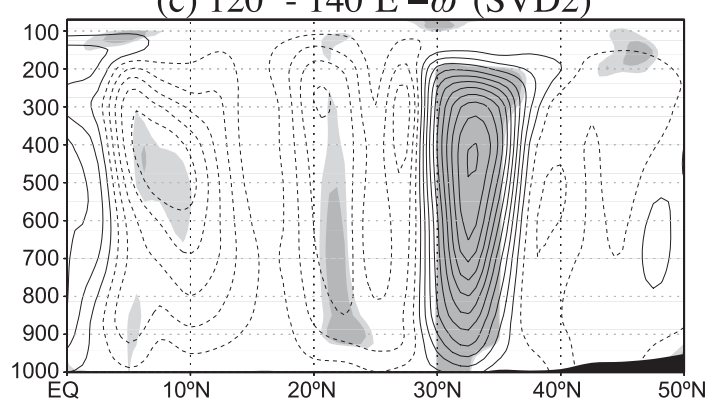

(b) $120^{\circ}-140^{\circ} \mathrm{E} Q_{1}^{\prime}(\mathrm{SVD} 1)$

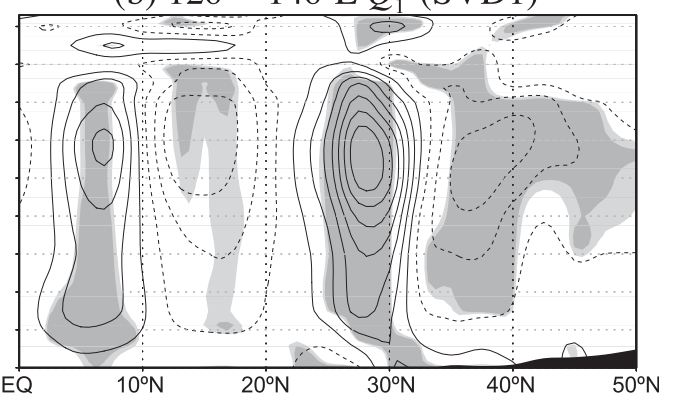

(d) $120^{\circ}-140^{\circ} \mathrm{E} Q_{1}^{\prime}(\mathrm{SVD} 2)$

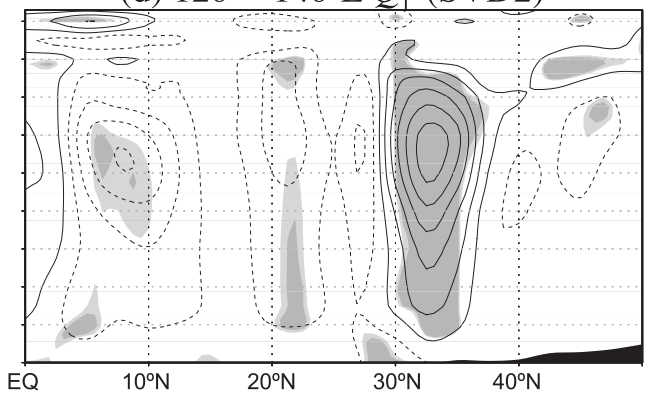

FIG. 5. (a),(c) Anomalous vertical $p$ velocity and (b),(d) $Q_{1}$ averaged over $120^{\circ}-140^{\circ} \mathrm{E}$ regressed onto the temporal coefficient of precipitation for (a),(b) SVD1 and (c),(d) SVD2, which are obtained for precipitation and 500-hPa horizontal temperature advection over $20^{\circ}-45^{\circ} \mathrm{N}, 110^{\circ}-170^{\circ} \mathrm{E}$ for early summer ( $\left.15 \mathrm{Jun}-14 \mathrm{Jul}\right)$. Contour interval in (a),(c) is $2( \pm 1, \pm 3, \pm 5, \ldots) \times 10^{-3} \mathrm{~Pa} \mathrm{~s}^{-1}$ and in (b),(d) is $0.2( \pm 0.1, \pm 0.3, \pm 0.5, \ldots) \mathrm{K} \mathrm{day}^{-1}$. In (a),(c), solid and dashed contours indicate anomalous ascent and descent, respectively. Light and dark shading represent the confidence levels of $90 \%$ and $95 \%$, respectively, based on the $t$ statistic.

the anomalous warm (cool) advection and precipitation increase (decrease) (Figs. 6a,c). This collocation is consistent with SX10's hypothesis that the warm (cool) advection induces ascent (descent) adiabatically and diabatic heating (cooling) amplifies ascent (descent). Instead of focusing on the 500-hPa temperature advection to clarify the causality by minimizing the first baroclinic contribution, we diagnose anomalous vertical motion $\omega^{\prime}$ that could be induced by adiabatic processes in the entire troposphere by using a linearized omega equation

$$
\begin{aligned}
\left(\nabla^{2}+\frac{f^{2}}{S^{2}} \frac{\partial^{2}}{\partial p^{2}}\right) \omega^{\prime}= & \frac{f}{S} \frac{\partial}{\partial p}\left[\overline{\mathbf{u}} \cdot \nabla \zeta^{\prime}+\mathbf{u}^{\prime} \cdot \nabla(f+\bar{\zeta})\right] \\
& +\frac{R}{S p} \nabla^{2}\left(\overline{\mathbf{u}} \cdot \nabla T^{\prime}+\mathbf{u}^{\prime} \cdot \nabla \bar{T}\right)
\end{aligned}
$$

In (1), $\omega$ denotes vertical $p$ velocity, $\zeta$ is (unsmoothed) relative vorticity, $f$ is the Coriolis parameter, and $p$ is pressure. Also, $S$ denotes the static stability $S=$ $(R / p)\left(R \bar{T} / c_{p} p-\partial \bar{T} / \partial p\right)$ with the gas constant $R$ and the specific heat at constant pressure $c_{p}$. Overbars indicate climatological-mean quantities, while variables with primes, except in $\omega^{\prime}$, are anomalies regressed onto the temporal coefficient of precipitation for SVD1 (Fig. 6b) or SVD2 (Fig. 6d). Equation (1) is applied for the Northern Hemisphere with the bottom and top boundaries at the 1000- and 70-hPa levels, respectively.

Since our diagnosis (1) includes no contribution from anomalous diabatic heating, the diagnosed vertical motion (Figs. 6b,d) is weaker than its observational counterpart in the corresponding regressed anomalies (Figs. 6a,c). Nevertheless, the omega-equation diagnosis reproduces the gross pattern of observed anomalous vertical motion in the midlatitudes. Specifically, anomalous ascent and descent are found with the anomalous midtropospheric warm and cool advection, respectively, indicating the importance of adiabatic induction of anomalous vertical motion by horizontal circulation anomalies. A southwestern intensification of the regressed anomalous ascent (Figs. 6a,c) compared to the omega-equation diagnosis (Figs. 6b,d) indicates an inhomogeneous moist feedback, which depends on the mean moisture (Fig. 1e).

In the omega equation, both thermal advection and differential vorticity advection [the second and first terms in the rhs of (1), respectively] contribute to vertical motion. The latter may include baroclinic response to latent heating. To remove this diabatic effect, we have repeated 
(a) $500 \mathrm{hPa}-\omega^{\prime}(\mathrm{SVD} 1)$

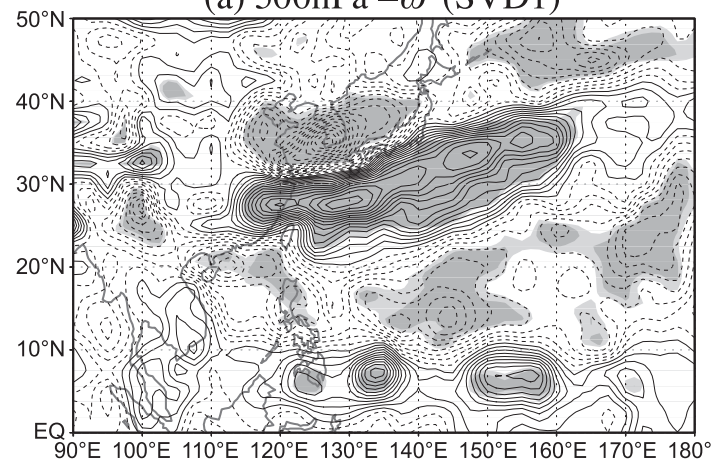

(c) $500 \mathrm{hPa}-\omega^{\prime}(\mathrm{SVD} 2)$

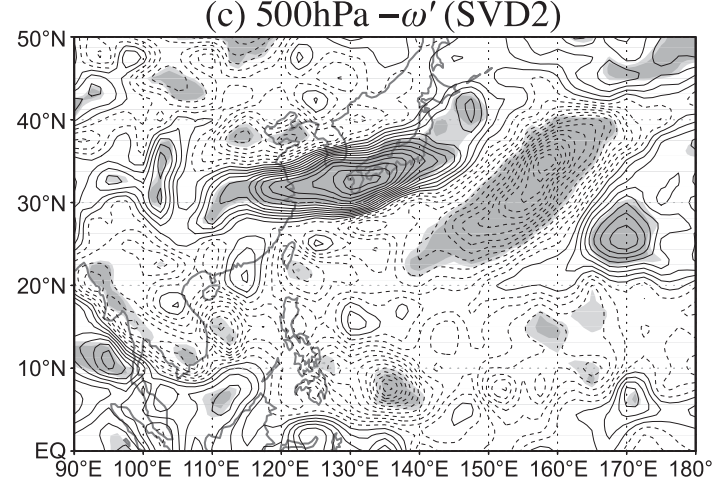

(b) 500hPa omega eq. solution (SVD1)

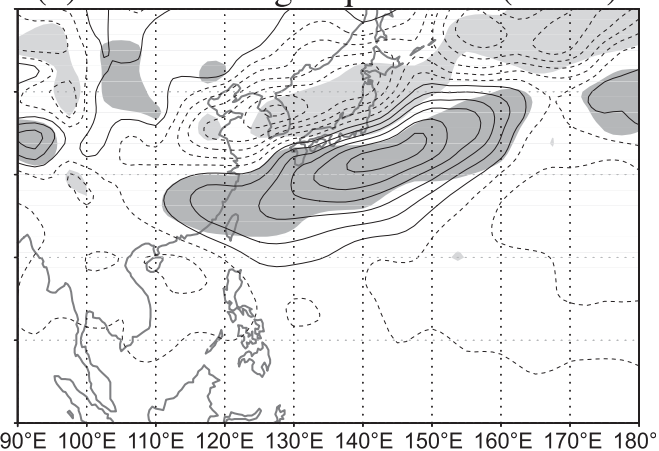

(d) $500 \mathrm{hPa}$ omega eq. solution (SVD2)

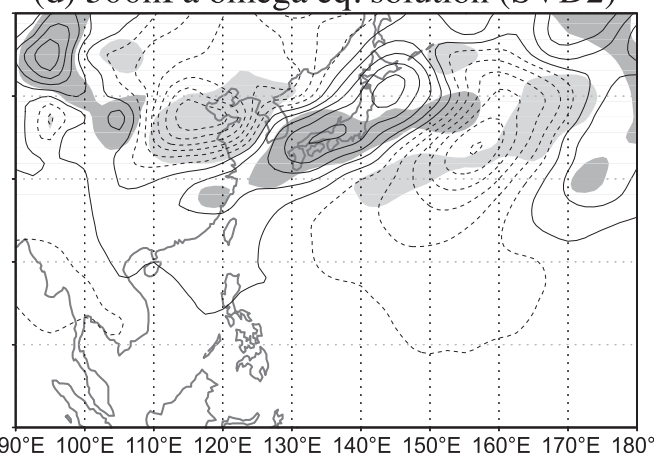

FIG. 6. (a),(c) Anomalous vertical $p$ velocity at the 500-hPa level regressed onto the temporal coefficient of precipitation for (a) SVD1 and (c) SVD2, which are obtained for precipitation and 500-hPa horizontal temperature advection over $20^{\circ}-45^{\circ} \mathrm{N}, 110^{\circ}-170^{\circ} \mathrm{E}$ for early summer (15 Jun-14 Jul). (b), (d) Anomalous vertical $p$ velocity at the $500-\mathrm{hPa}$ level diagnosed on the basis of the linearized omega equation with regressed horizontal wind, (unsmoothed) vorticity, and temperature anomalies for (b) SVD1 and (d) SVD2. Contour interval is $2( \pm 1, \pm 3, \pm 5, \ldots) \times 10^{-3}$ $\mathrm{Pa} \mathrm{s}^{-1}$, with solid and dashed contours indicating anomalous ascent and descent, respectively. Light and dark shading in (a),(c) represent the confidence levels of $90 \%$ and $95 \%$, respectively, based on the $t$ statistic. In (b),(d), they indicate anomalous descent and ascent, respectively, of $2 \times 10^{-3} \mathrm{~Pa} \mathrm{~s}^{-1}$ in magnitude, diagnosed from the omega equation using the anomalous temperature advection only.

the diagnosis based solely on the anomalous temperature advection (shading in Figs. 6b,d). The anomalous ascent (descent) diagnosed in this way again lies in the vicinity of enhanced (reduced) precipitation, especially for SVD1 (Fig. 6b). This collocation suggests the robustness of our analysis since this diagnosis includes influences from the entire troposphere.

For SVD2, a discrepancy is found in the anomalous ascent east of Japan (Fig. 6d). Although anomalous ascent diagnosed around northern Japan with the full advection (north of $40^{\circ} \mathrm{N}$ in Fig. $6 \mathrm{~d}$ ) that is consistent with the regression map (Fig. 6c), it is out of the climatologically moist region and therefore not strongly related to local precipitation anomalies. Indeed, the anomalous precipitation is insignificant around this local maximum of anomalous ascent (Fig. 4a). This ascent is absent in the diagnosis based on anomalous temperature advection (shading in Fig. 6d), whose zonal orientation looks more consistent with precipitation anomalies (Fig. 4a) than that diagnosed with the full advection.
The adiabatically induced anomalous ascent can trigger or reinforce local precipitation while the corresponding anomalous descent acts to suppress it. The precipitation anomalies, in turn, act to strengthen the anomalous vertical motion locally through anomalous diabatic heating, to form a feedback loop. Differences in amplitudes of anomalous vertical motion between the regression and omega-equation diagnosis measures the efficiency of this moist feedback, which roughly trebles the anomalous vertical motion.

\section{c. Transient eddy activity}

Figure 7 indicates anomalies in column-integrated moisture flux convergence associated with SVD1 and SVD2. Moisture flux convergence can be related to precipitation $P$ through

$$
-\int_{0}^{p_{s}} \nabla \cdot(q \mathbf{u})^{\prime} d p / g=P^{\prime}-E^{\prime}
$$



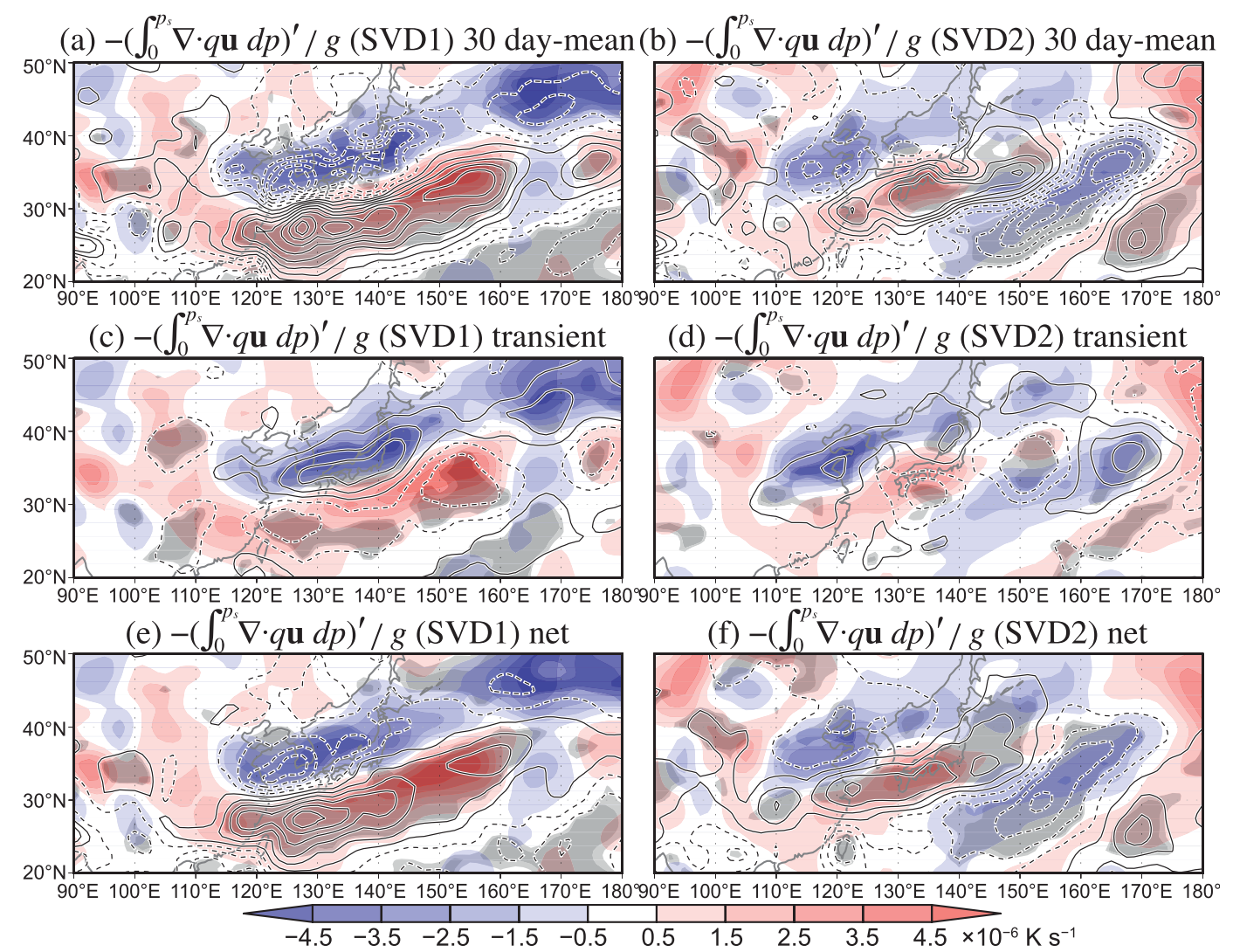

FIG. 7. Column-integrated horizontal convergence anomalies of specific humidity flux regressed onto the temporal coefficient of precipitation for (a),(c),(e) SVD1 and (b),(d),(f) SVD2, which are obtained for precipitation and 500-hPa horizontal temperature advection over $20^{\circ}-45^{\circ} \mathrm{N}, 110^{\circ}-170^{\circ} \mathrm{E}$ for early summer (30 days for $15 \mathrm{Jun}-14 \mathrm{Jul}$ ). Specific humidity flux is calculated in (a),(b) with 30-day-mean fields, in (c),(d) with deviations from the 30-day mean, and in (e),(f) with their sum. Contour interval is $0.6( \pm 0.3, \pm 0.9, \pm 1.5, \ldots) \times 10^{-5} \mathrm{~kg} \mathrm{~m}^{-2} \mathrm{~s}^{-1}$, with solid and dashed lines indicating anomalous convergence and divergence, respectively. Light and dark gray shading represent the confidence levels of $90 \%$ and $95 \%$, respectively, based on the $t$ statistic. Colored shading indicates $500-\mathrm{hPa}$ anomalous temperature advection (Figs. $3 c$ and $4 b$ ).

where $q$ is specific humidity, $p_{s}$ is surface pressure, $E$ is evaporation, and $g$ is the gravitational acceleration. In evaluating the left-hand side of (2), the convergence has been decomposed into two components: a stationary component that consists of 30-day-mean fields of specific humidity, wind velocity, and surface pressure, and a contribution from transient variability (i.e., departures from 30-day-mean fields).

Anomalous moisture flux convergence and divergence shown in Fig. 7 basically coincide with midtropospheric warm and cool advection anomalies, respectively, in the stationary component (Figs. 7a,b), although the inhomogeneities in the climatological humidity slightly reduce the geographical correspondence of local maxima and minima between the two variables. The coincidence is nevertheless conspicuous in SVD1 in the mei-yu-baiu region (Fig. 7a), while in SVD2 the anomalous moisture flux convergence partly overlaps the anomalous cool advection southeast of Japan (Fig. 7b). In SVD2, however, the moisture flux convergence tends to be more consistent with the diagnosis for temperature advection (Fig. 6d), indicating an important contribution from the lower- and upper-tropospheric temperature advection. Except this slight discrepancy, the coincidence between moisture divergence/convergence and temperature advection is consistent with the dynamical induction of anomalous precipitation.

Figure 7 indicates that moisture transport by transient eddies tends to offset the contribution from the stationary component (Figs. 7c,d), although the former contribution is generally smaller than the latter. A close inspection reveals that the transient component tends to be displaced slightly southward (Figs. 7c,d). Precipitation increase over China captured in SVD2 is displaced northward compared to both the anomalous warm advection (Figs. 4, 7f) and the stationary component of 
(a) $850 \mathrm{hPa} \zeta^{\prime}($ SVD1)

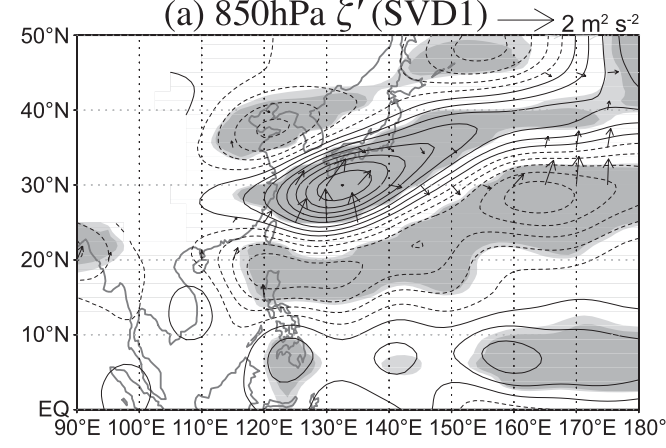

(c) $850 \mathrm{hPa} \zeta^{\prime}(\mathrm{SVD} 2) \longrightarrow 2 \mathrm{~m}^{2} \mathrm{~s}^{-2}$

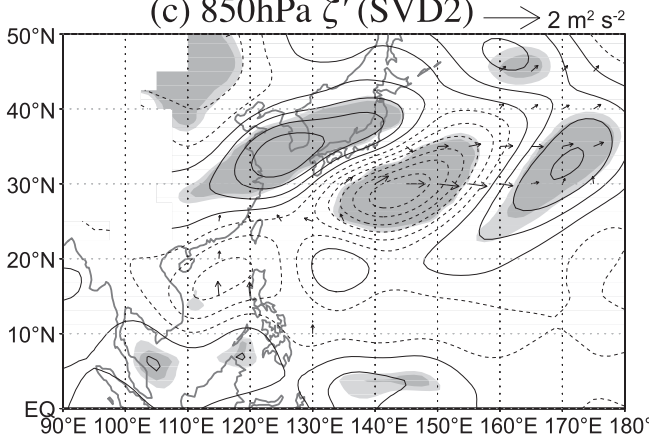

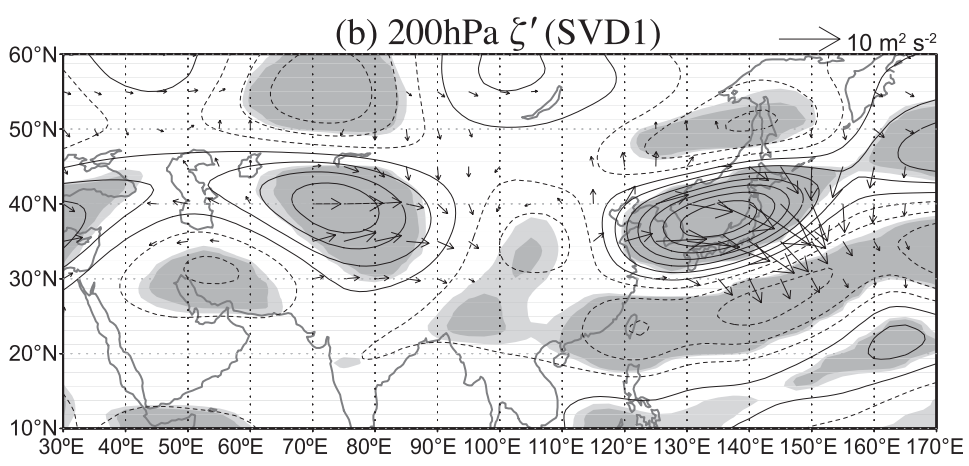

(d) $200 \mathrm{hPa} \zeta^{\prime}(\mathrm{SVD} 2)$

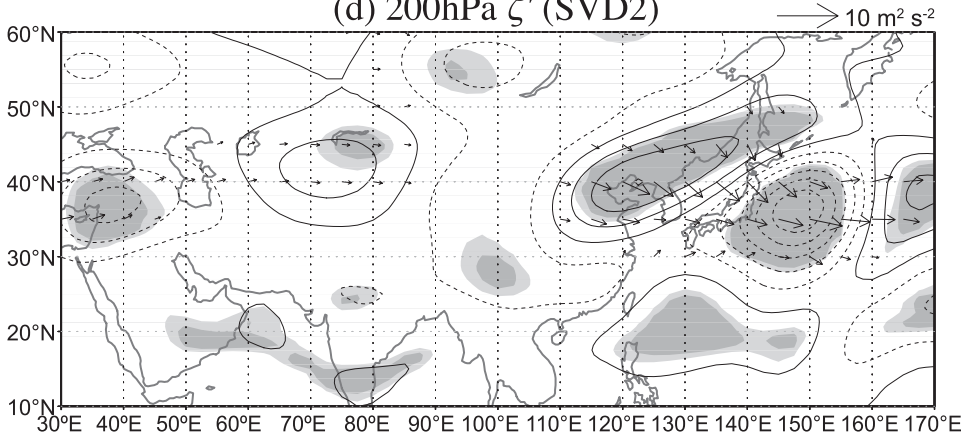

FIG. 8. (a),(c) 850- and (b),(d) 200-hPa vorticity anomalies regressed onto the temporal coefficient of precipitation for (a),(b) SVD1 and (c), (d) SVD2 between precipitation and 500-hPa horizontal temperature advection over $20^{\circ}-45^{\circ} \mathrm{N}, 110^{\circ}-170^{\circ} \mathrm{E}$ for early summer $(15 \mathrm{Jun}-$ $14 \mathrm{Jul})$. Contour interval in (a),(c) is $0.6( \pm 0.3, \pm 0.9, \pm 1.5, \ldots)$ and in (b),(d) is $2( \pm 1, \pm 3, \pm 5, \ldots) \times 10^{-6} \mathrm{~s}^{-1}$. Light and dark shading represent the confidence levels of $90 \%$ and $95 \%$, respectively, based on the $t$ statistic. The wave activity flux formulated by Takaya and Nakamura (2001), calculated by using the regressed anomalies, is indicated by arrows with the scale at the top of each panel.

moisture convergence (Fig. 7b). The transient moisture convergence (Fig. 7d) contributes to this displacement. How the changes in the activity of transient eddies and their moisture transport are induced in association with the interannual variability of mei-yu-baiu precipitation is unclear and needs to be addressed in future studies.

\section{d. Teleconnections}

Anomalous circulation associated with SVD1 exhibits wavelike anomalies along the upper-tropospheric Asian jet $\left(\sim 40^{\circ} \mathrm{N}\right)$ over the Eurasian continent (Fig. 8b), indicating an association of the mei-yu-baiu precipitation variability with the Silk Road pattern (Enomoto et al. 2003; Enomoto 2004; Kosaka et al. 2009), which may be a component of the summertime circumglobal teleconnection pattern (Ding and Wang 2005; Yasui and Watanabe 2010). In the particular polarity shown, the pattern features anomalous cyclonic circulation elongated zonally over the Korean Peninsula and Japan (Fig. $8 b)$. To its south, anticyclonic anomalous circulation is noticeable, which forms a meridional dipole of vorticity anomalies together with the midlatitude anomalous cyclone. This anomaly dipole extends into the lower troposphere (Fig. 8a), with a notable equatorward displacement relative to its upper-tropospheric counterpart. The dipole features poleward and equatorward wave activity fluxes in the lower and upper troposphere, respectively (Figs. 8a,b), and reduced precipitation around the northern Philippines and to its east (Figs. 3a,b). These are characteristics of the PJ pattern (Nitta 1987; Huang and Sun 1992; Kosaka and Nakamura 2006, 2010). These results thus suggest that the precipitation anomalies in early summer are induced, at least partly, by remote influences through the PJ and Silk Road teleconnection patterns (Hsu and Lin 2007) via anomalous midtropospheric thermal advection in the vicinity of the climatological mei-yu-baiu rainband. Meanwhile, $\mathrm{Lu}$ and Lin (2009) pointed out that anomalous diabatic heating associated with the mei-yu-baiu precipitation anomalies can reinforce the upper-tropospheric PJ anomalous circulation in the midlatitudes. In their dry, linear baroclinic model, midlatitude heating is prescribed independently of tropical diabatic cooling. Their study and ours suggest the possibility that anomalous circulation as a response to anomalous tropical heating can modify midtropospheric thermal advection and thereby induce precipitation and upper-tropospheric circulation anomalies in the midlatitudes. 
(a) $P^{\prime}$ (heterogeneous)

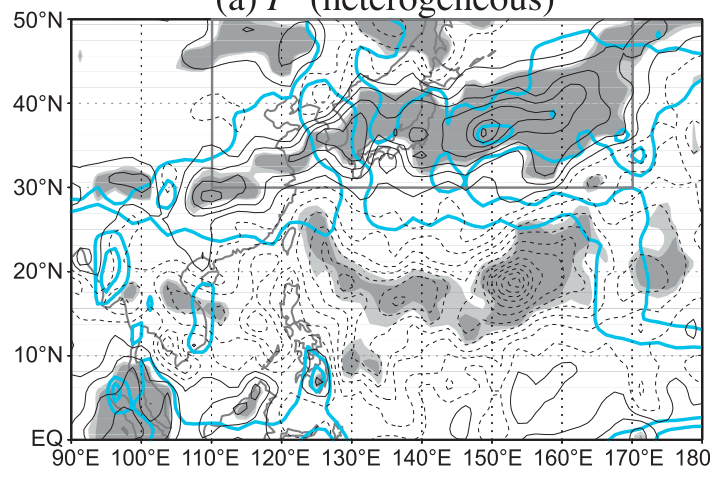

(c) $500 \mathrm{hPa}-\omega^{\prime}$

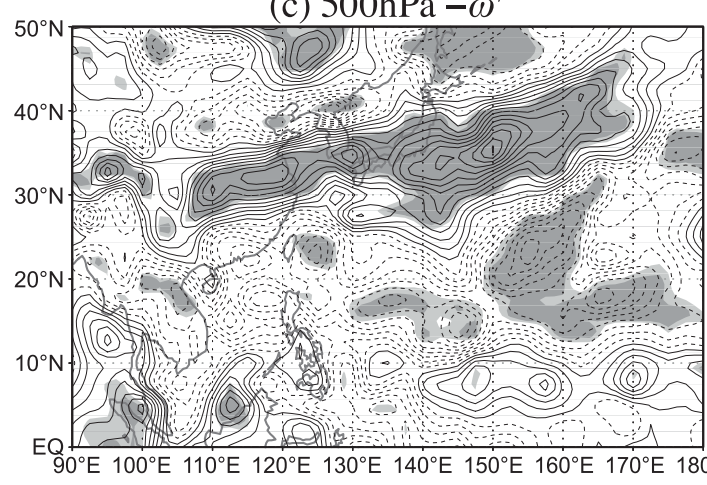

(b) $500 \mathrm{hPa}-(\mathbf{u} \cdot \nabla T)^{\prime}$ (heterogeneous), $\mathbf{u}^{\prime}, \bar{T}$

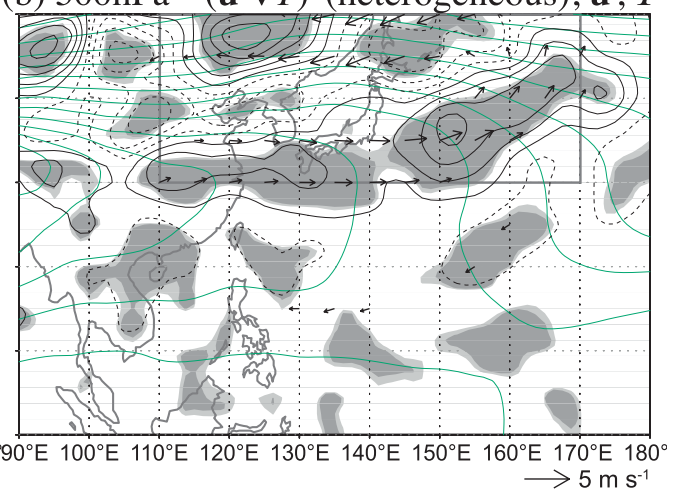

(d) $500 \mathrm{hPa}$ omega eq. solution

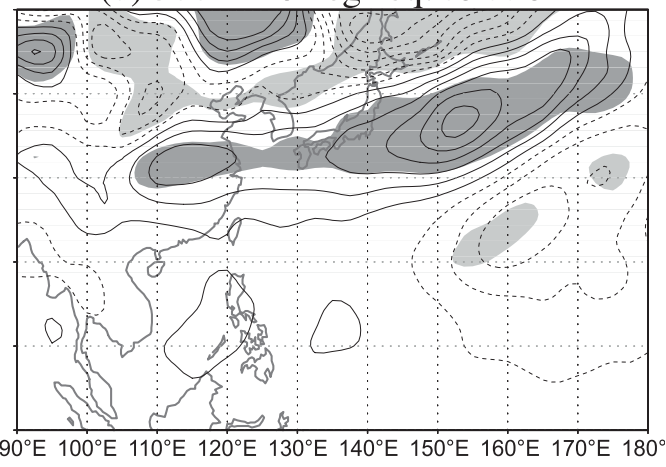

FIG. 9. (a)-(d) As in Figs. 3b, 3c, 6a, and 6b, respectively, but for SVD1 between precipitation and 500-hPa horizontal temperature advection over $30^{\circ}-50^{\circ} \mathrm{N}, 110^{\circ}-170^{\circ} \mathrm{E}$, as indicated by boxes with thick lines in (a), (b), for midsummer (20 Jul-18 Aug). Light blue contours in (a) indicate climatological-mean precipitation of 4 and $6 \mathrm{~mm}$ day $^{-1}$.

Possibly through the Indian Ocean capacitor effect, the PJ pattern can be excited via precipitation anomalies over the South China Sea and east of the Philippines in summers after ENSO events (Xie et al. 2009). Therefore, the PJ signal in SVD1 is consistent with the correlation of SVD1 with ENSO in the preceding winter and IOBM in the concurrent summer (Table 1). It suggests a vital role of the PJ pattern in the delayed impact of ENSO on the anomalous mei-yu-baiu precipitation.

Though less significant, a wavelike anomaly pattern is noticeable in SVD1 along the upper-tropospheric polarfront jet near $60^{\circ} \mathrm{N}$ (Fig. $8 \mathrm{~b}$ ). This wave train often leads to the formation of the surface Okhotsk high (Nakamura and Fukamachi 2004), which occasionally brings anomalous cool northeasterlies to northeastern Japan (Kodama 1997) and an increase of baiu precipitation (Wang 1992).

In SVD2, signature of PJ-like meridional teleconnection is less conspicuous (Figs. 8c,d). In the upper troposphere, a cyclonic anomaly centered near $75^{\circ} \mathrm{E}$ with an eastward wave activity flux may be a hint of a wave train along the East Asian jet (Fig. 8d), with a slight poleward displacement compared to its counterpart in SVD1 (Fig. 8b).

\section{Midsummer}

Climate over the WNP and East Asia undergoes marked changes from early summer to midsummer (section 3). The SVD analysis is repeated for the midsummer period over a domain $\left(30^{\circ}-50^{\circ} \mathrm{N}, 110^{\circ}-170^{\circ} \mathrm{E}\right)$, which is defined on the basis of Fig. $2 d$ to exclude the tropical rainband. Squared covariance fractions accounted for by midsummer SVD1 and SVD2 are $46.5 \%$ and $16.8 \%$, respectively, and the correlation between the time series corresponding to the temperature advection and precipitation is high for each of these modes (Table 1). The associated anomalous diabatic heating and vertical motion are strongest in the midtroposphere around the mei-yu-baiu rainband (figure not shown), justifying our choice of the 500-hPa level for horizontal temperature advection. The midsummer distribution of anomalous precipitation extracted in SVD1 is very similar to that of the leading EOF mode obtained for precipitation over the same domain, with their pattern correlation of 0.89 , while the corresponding relationship between the midsummer SVD2 and the corresponding second EOF mode is moderate (their pattern 


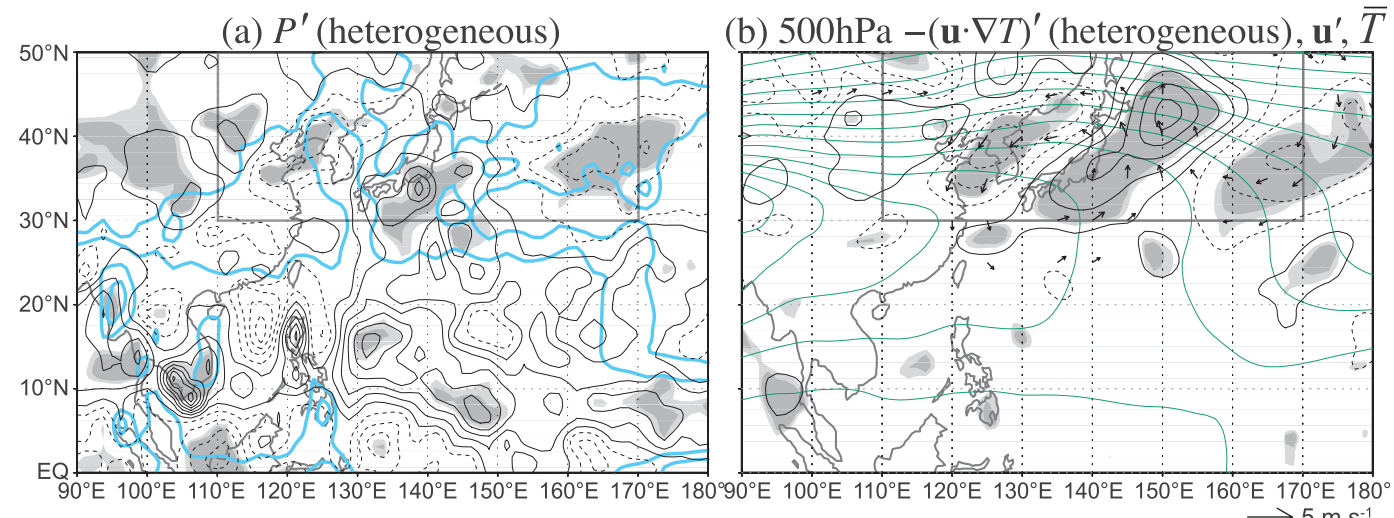

(c) $500 \mathrm{hPa}-\omega^{\prime}$

(d) $500 \mathrm{hPa}$ omega eq. solution

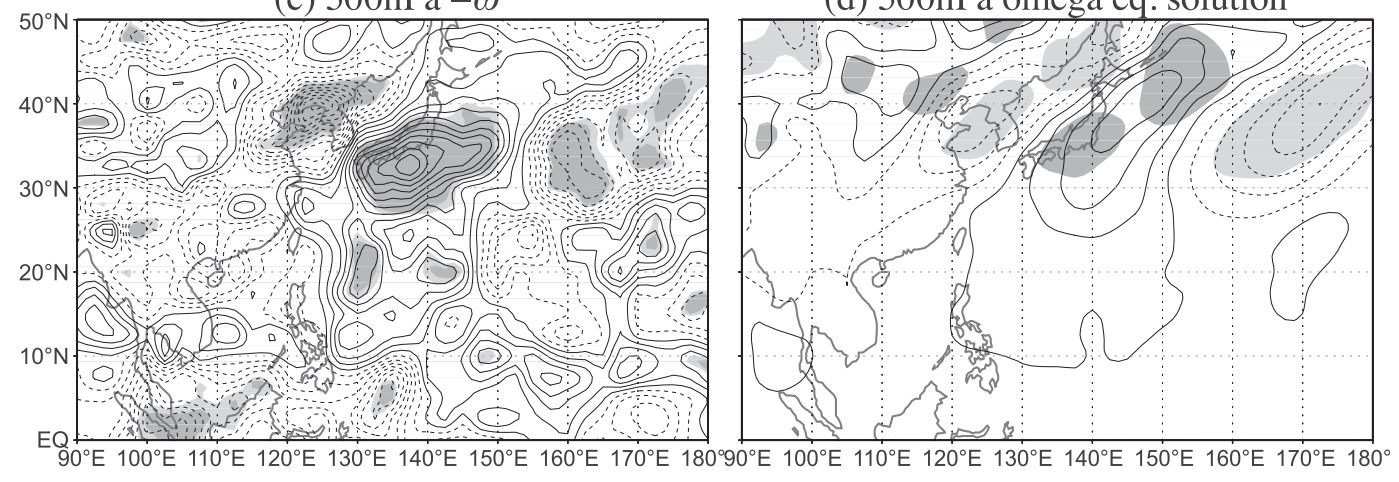

FIG. 10. As in Fig. 9, but obtained for SVD2.

correlation: 0.50). Midsummer SVD1 is significantly correlated with the El Niño index in $\mathrm{D}(-1) \mathrm{JF}(0)$ and the IOBM index in JJA(0) (Table 1), again indicative of the Indian Ocean capacitor effect (Xie et al. 2009). Correlation with IOBM is even higher in midsummer than in early summer (Table 1 ).

Figure 9 shows anomaly fields regressed onto the temporal coefficient of precipitation for midsummer SVD1. In the particular polarity shown in Fig. 9, enhanced precipitation is located over the Yangtze River valley, South Korea, central and northern Japan, and farther to the east (Fig. 9a). In contrast to the early summer case (Fig. 3), midsummer SVD1 represents an intensification of the entire mei-yu-baiu rainband (Fig. 9a). A zonally elongated region of anomalous warm advection (Fig. 9b) is almost collocated with enhanced precipitation (Fig. 9a) and anomalous ascent (Fig. 9c) over China and east of Japan. The warm advection is slightly displaced southward in a sector that covers the Korean Peninsula and Japan. As seen later in our moisture budget analysis, this displacement may be due to a discrepancy between JRA-25 reanalysis and CMAP data. To the north of $45^{\circ} \mathrm{N}$, a zonal dipole of positive and negative anomalies in precipitation is evident (Fig. 9a). These precipitation anomalies are in fairly good correspondence with anomalies in vertical motion (Fig. 9c) and midtropospheric thermal advection (Fig. 9b), although the advection anomalies are displaced slightly eastward relative to the corresponding anomalous precipitation. Except the meridional displacement over the Korean/Japanese sector, the midsummer anomalies of midtropospheric temperature advection are overall consistent with the anomalous vertical motion and precipitation. These results suggest that SX10's mechanism is applicable also to interannual variability of midsummer precipitation. Indeed, our diagnosis with the linearized omega equation indicates that the distribution of anomalous vertical motion (Fig. 9c) is consistent with that diagnosed solely from the anomalous temperature advection (Fig. 9d).

Midsummer SVD2 shows a less-organized distribution of precipitation and temperature advection anomalies (Figs. 10a,b). Still, significant increase and decrease in precipitation around southeastern Japan and the Yellow Sea, respectively, may represent a southeastward shift of the mei-yu-baiu rainband. These precipitation anomalies are associated with warm and cool advection anomalies. The negative precipitation anomaly west of the date line is also consistent locally with an anomalous cool advection. Compared to the anomalous warm advection (Fig. 10b) and diagnosed adiabatic ascent (Fig. 10d), the 

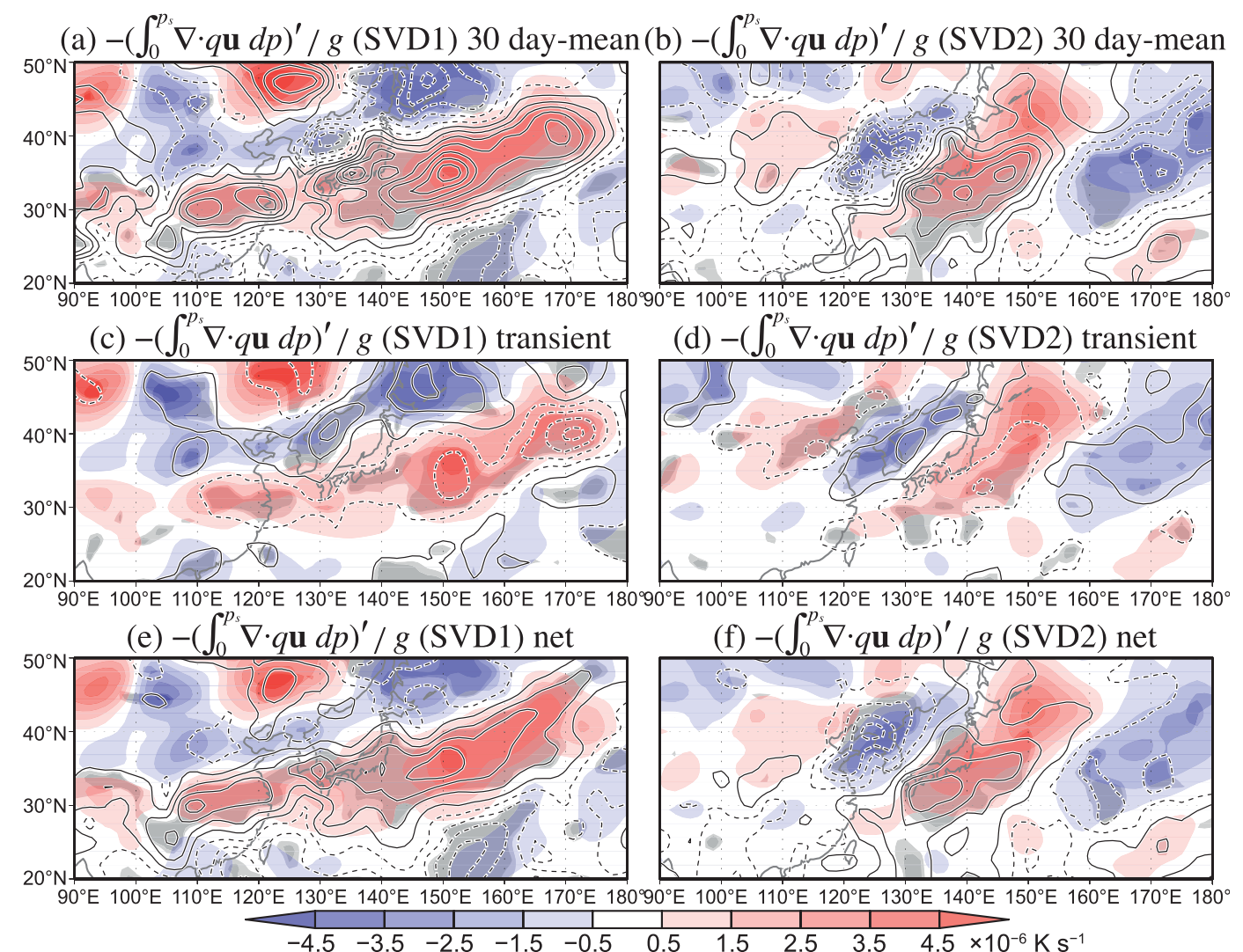

FIG. 11. As in Fig. 7, but for SVD1 and SVD2 between precipitation and 500-hPa horizontal temperature advection over $30^{\circ}-50^{\circ} \mathrm{N}, 110^{\circ}-170^{\circ} \mathrm{E}$ for midsummer (20 Jul-18 Aug).

precipitation increase (Fig. 10a) and regressed anomalous ascent (Fig. 10c) are suppressed to the north of $40^{\circ} \mathrm{N}$, possibly because of the lack of abundant moisture (Fig. 1f).

Anomalous convergence and divergence of the stationary component of the moisture flux for midsummer SVD1 generally coincide with the anomalous warm and cool advection, respectively (Fig. 11a). As in the early summer case (Fig. 7), the contribution from the transient component tends to oppose the contribution from the stationary component (Fig. 11c). For example, anomalous convergence due to the transient component almost cancels out anomalous divergence of the stationary component around the Korean Peninsula (Figs. 11a,c). The cancellation leaves virtually no anomaly in the net moisture flux divergence and precipitation decrease (Figs. 9a and 11e) that would otherwise be induced by anomalous cool advection locally (Fig. 9b). Transients help expand anomalous convergence over the East China Sea northward (Fig. 11e). Still, the net moisture convergence anomalies in SVD1 (Fig. 11e), which equal the anomalies in precipitation minus evaporation, exhibit an apparent discrepancy with CMAP precipitation anomalies (Fig. 9a), especially over the Sea of Japan and western Japan. This indicates a discrepancy in precipitation between the
JRA-25 and CMAP data. Indeed, the regressed anomalies in vertical motion (Fig. 9c) and precipitation (not shown) both based on JRA-25 are more consistent with the anomalous moisture convergence/divergence shown in Fig. 11e than with CMAP precipitation anomalies (Fig. 9a).

In midsummer SVD2, anomalous moisture flux convergence and divergence due to the stationary component generally overlap the anomalous warm and cool advection, respectively, though the anomalous moisture convergence tends to be suppressed north of $40^{\circ} \mathrm{N}$ (Fig. 11b). The transient component (Fig. 11d) partially offsets the contribution from the stationary component. It also contributes to the northward displacement of the anomalous moisture divergence by the stationary component centered at the Korean Peninsula (Fig. 11b), which is in better correspondence with the anomalous cold advection (Fig. 10b). With this displacement included, the net anomalous moisture divergence (Fig. 11f) coincides with the precipitation anomalies (Fig. 10a).

Anomalous circulation and wave activity flux in association with midsummer SVD1 (Figs. 12a,b) feature the PJ pattern in its particular phase with reduced precipitation over the tropical WNP near $\left(19^{\circ} \mathrm{N}, 153^{\circ} \mathrm{E}\right)$ (Fig. 9a). In contrast to the early summer case, neither the Silk 
(a) $850 \mathrm{hPa} \zeta^{\prime}(\mathrm{SVD} 1)$

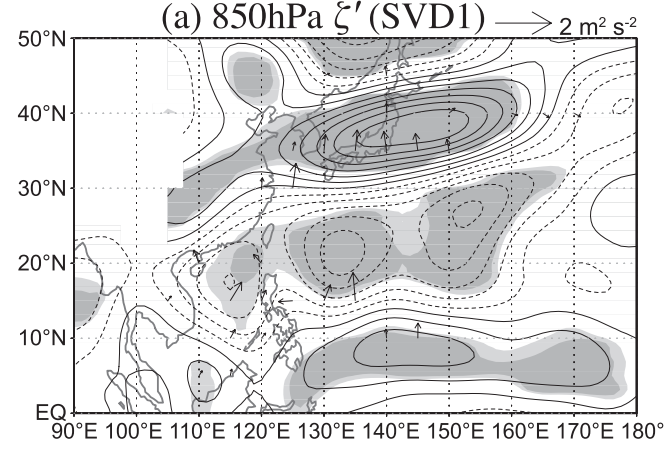

(c) $850 \mathrm{hPa} \zeta^{\prime}(\mathrm{SVD} 2) \longrightarrow 2 \mathrm{~m}^{2} \mathrm{~s}^{-2}$

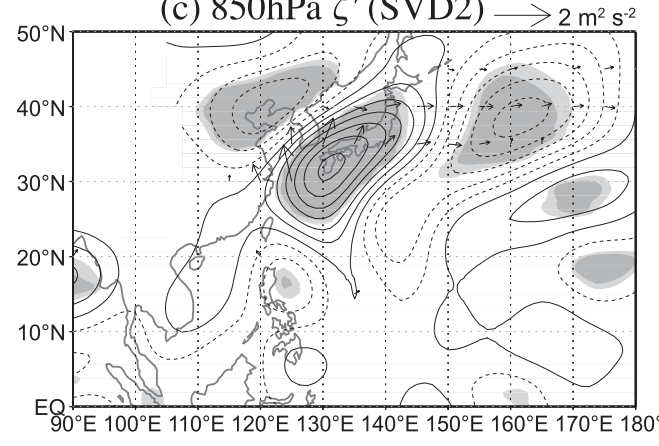

(b) $200 \mathrm{hPa} \zeta^{\prime}(\mathrm{SVD} 1)$

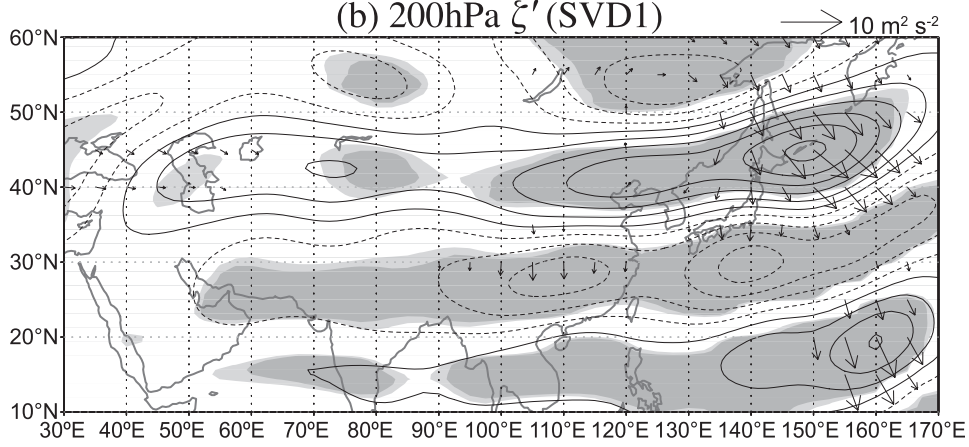

(d) $200 \mathrm{hPa} \zeta^{\prime}$ (SVD2)

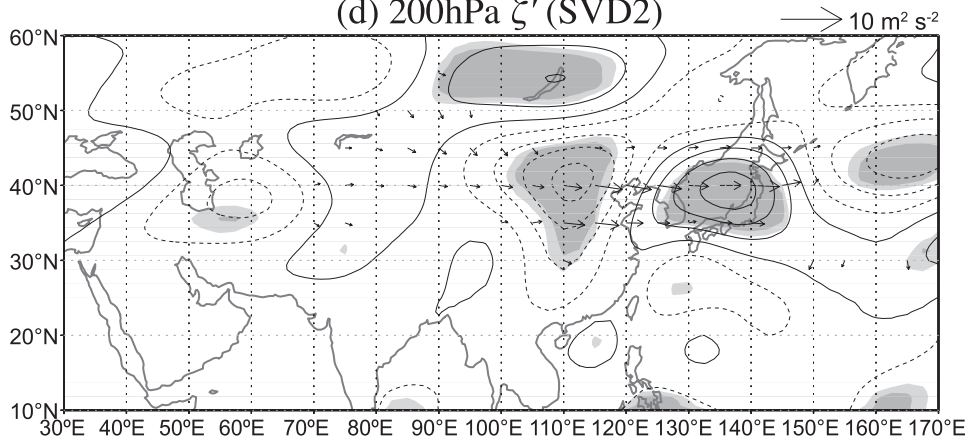

FIG. 12. As in Fig. 8, but for SVD1 and SVD2 between precipitation and 500-hPa horizontal temperature advection over $30^{\circ}-50^{\circ} \mathrm{N}, 110^{\circ}-$ $170^{\circ} \mathrm{E}$ for midsummer (20 Jul-18 Aug).

Road pattern nor the wave train pattern along the polarfront jet is involved in midsummer SVD1 (Fig. 12b). The absence of the signal of the Silk Road pattern in midsummer SVD1 is consistent with Kosaka et al. (2009), who indicated a coexistence of the PJ and Silk Road patterns for July but not for August. Since the Silk Road pattern is not correlated with ENSO in the preceding winter, the lack of its interference with the PJ pattern seems to explain higher correlation of midsummer SVD1 with IOBM compared to the early summer case (Table 1). For SVD2, in contrast, the associated circulation anomalies include no signature of the PJ-like meridional teleconnection (Figs. 12c,d). Instead, a wave train is evident that originates from central Siberia extending southeastward into Japan (Fig. 12d). Though statistically insignificant, cyclonic and anticyclonic anomalies are found upstream along the Asian and polar-front jets, implying a coherent occurrence of two wave trains along these jets found by Iwao and Takahashi (2008).

\section{Joint interannual migration of warm advection and mei-yu-baiu rainband}

Analyses in sections 4 and 5 are based on the SVD method. However, not all the anomalies in precipitation and the midtropospheric thermal advection can be projected onto the leading SVD modes. Latitudinal maxima and minima of these anomalies are detected in individual years within different longitudinal sectors. Based on climatological-mean precipitation (Figs. 1c,d), the sectors for analysis are defined as eastern China $\left(110^{\circ}-\right.$ $120^{\circ}$ E; Fig. 13a), Korea-Japan $\left(125^{\circ}-140^{\circ}\right.$ E; Fig. 13b), and east of Japan $\left(145^{\circ}-160^{\circ} \mathrm{E}\right.$; Fig. $\left.13 \mathrm{c}\right)$ for early summer; and eastern China-East China Sea $\left(115^{\circ}-130^{\circ} \mathrm{E}\right.$; Fig. 13d) and east of Japan (Fig. 13e) for midsummer.

For early summer (Figs. 13a-c), the southwestnortheast tilt of the climatological maxima for both precipitation and the temperature advection (shown at the right and bottom plots of each panel of Fig. 13, respectively) is apparent as their maxima shift northward from the western to eastern sectors (from Fig. 13a to Fig. 13c). The latitudes of the extremes of their anomalies, which are identified around their climatological-mean maxima, exhibit an apparent interannual correlation in each of the sectors (Figs. 13a-c). For midsummer (Figs. $13 \mathrm{~d}, \mathrm{e})$, the collocation of the maxima for precipitation and the temperature advection is somewhat ambiguous in climatology (section 3), but the covariability is nevertheless apparent in latitude between the anomaly maxima of precipitation and the temperature advection, especially for the eastern China-East China Sea $\left(115^{\circ}-\right.$ $130^{\circ} \mathrm{E}$ ) sector (Fig. 13d). As a result independent of the 
(a) $110^{\circ}-120^{\circ} \mathrm{E}$ early summer

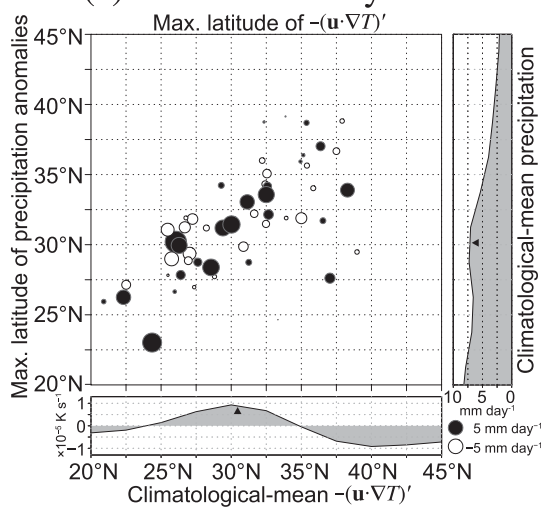

(b) $125^{\circ}-140^{\circ} \mathrm{E}$ early summer

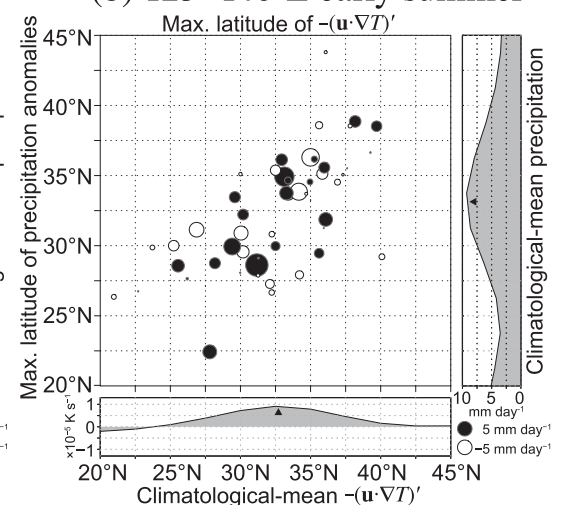

(c) $145^{\circ}-160^{\circ} \mathrm{E}$ early summer

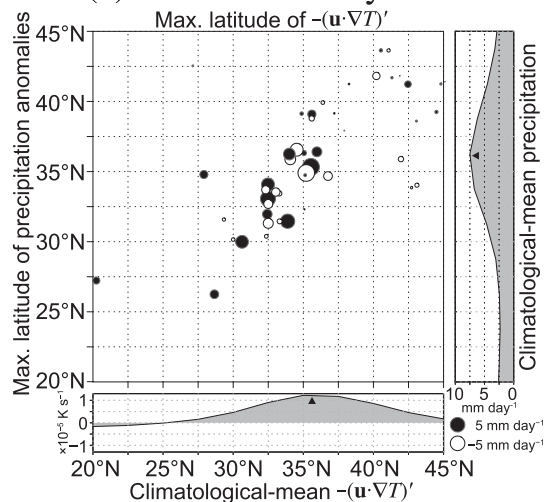

(d) $115^{\circ}-130^{\circ} \mathrm{E}$ midsummer

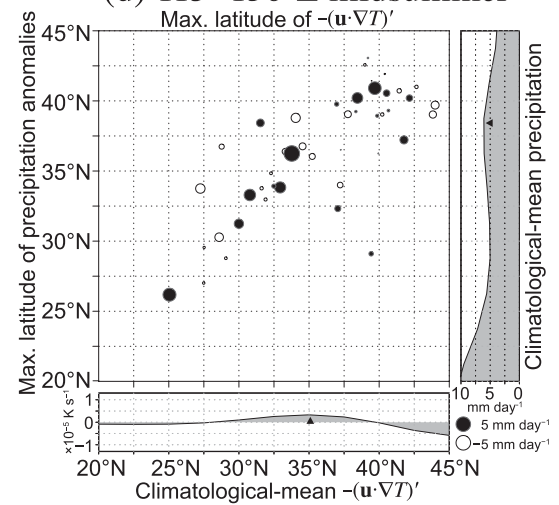

(e) $145^{\circ}-160^{\circ} \mathrm{E}$ midsummer

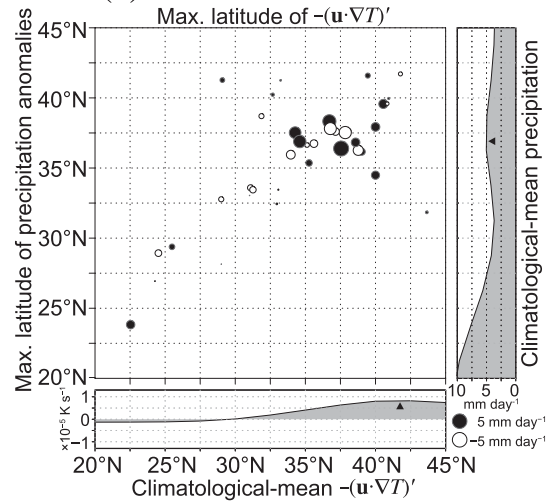

FIG. 13. Scatter diagrams illustrating covariability in latitudes where local extremes of anomalies achieved between (abscissa) horizontal temperature advection at the 500-hPa level and (ordinate) precipitation for each year from 1979 to 2007 for (a)-(c) early summer (15 Jun$14 \mathrm{Jul}$ ) and (d),(e) midsummer (20 Jul-18 Aug). After anomalies have been averaged over (a) $110^{\circ}-120^{\circ} \mathrm{E}$, (b) $125^{\circ}-140^{\circ} \mathrm{E},(\mathrm{c}),(\mathrm{e}) 145^{\circ}-$ $160^{\circ} \mathrm{E}$, and (d) $115^{\circ}-130^{\circ} \mathrm{E}$, the local maxima and minima are calculated through the spline interpolation method so that the pair of maximum and minimum for each year straddles climatological-mean maximum of the corresponding variable. Closed (open) circles indicate local maxima (minima), whose diameters are proportional to the magnitudes of precipitation anomalies, with a scale given at the right bottom of each panel. Climatology of horizontal temperature advection at the 500-hPa level and precipitation is shown at the bottom and right of each panel, respectively, with triangles indicating climatological maxima.

SVD method, Fig. 13 thus suggests that the mei-yu-baiu precipitation and the midtropospheric warm advection migrate jointly in interannual variability.

\section{Summary and discussion}

\section{a. Summary and a conceptual model}

In the present study, interannual variability in summer precipitation associated with the mei-yu-baiu rainband has been investigated in relation to large-scale atmospheric circulation. Our SVD analysis between midtropospheric temperature advection and precipitation indicates the overall collocation of these anomalies (Figs. 3, 4, 9, 10, and 13). This result suggests that the formation mechanism of the mei-yu-baiu rainband proposed by SX10 is applicable also to interannual variability. Moisture transport by transient eddies appears to counteract the induction of anomalous precipitation by the midtropospheric temperature advection. This opposing effect by transient eddies causes slight displacements of precipitation and midtropospheric temperature advection anomalies.

The above results lead us to propose a conceptual model for interannual variability of mei-yu-baiu rainfall (Fig. 14). In boreal summer, between the climatologically warmer Asian continent and cooler North Pacific forms a strong east-west thermal gradient. Embedded in this background state, remotely forced circulation anomalies cause changes in horizontal temperature advection, which adiabatically induce anomalous vertical motion and precipitation. The circulation anomalies are related with the PJ pattern, the Silk Road pattern along the Asian jet, and/or a wave train pattern along the polar-front jet. The adiabatically induced anomalous ascent enhances rainfall in the mei-yu-baiu rainband, and 


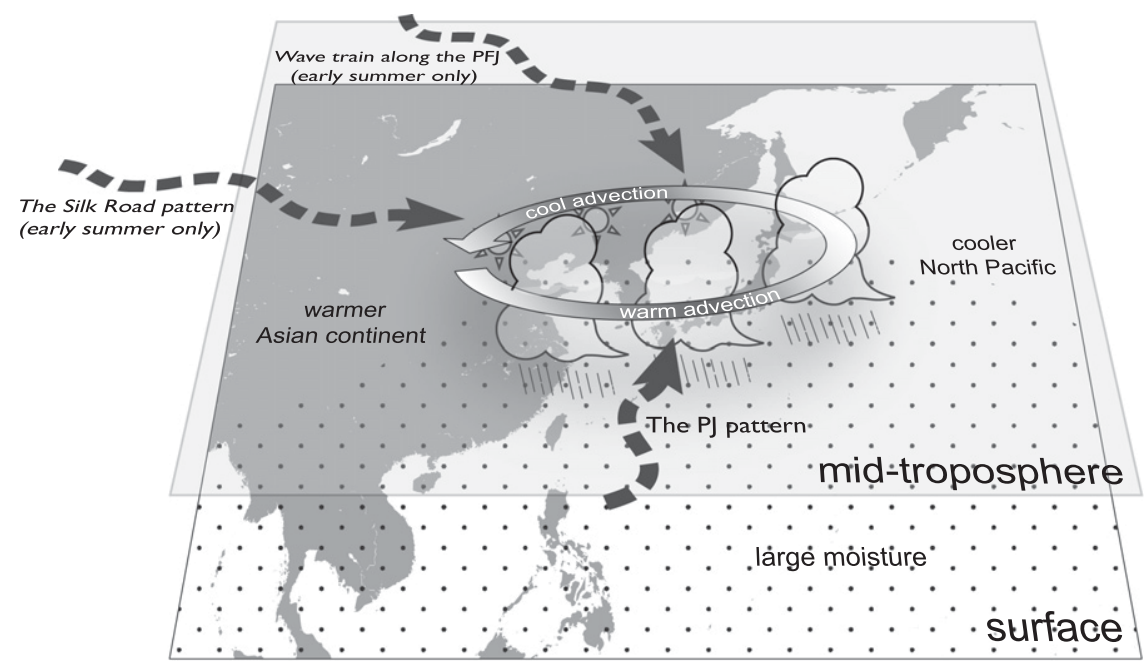

FIG. 14. A schematic diagram describing the conceptual model for interannual variability of mei-yu-baiu rainfall. Anomalous westerlies and easterlies in the mei-yu-baiu region (solid arrow) are accompanied by anomalous ascending and descending motions, respectively, in the midtroposphere. In the region with climatologically high moisture indicated by stippling, the anomalous ascent (descent) reinforces (suppresses) local precipitation, as described by symbols of cloud (sun). The anomalous circulation can be induced by three atmospheric teleconnection patterns (broken arrows).

the resultant anomalous diabatic heating reinforces the anomalous vertical motion, forming a feedback system.

\section{b. Discussion}

Currently, global atmospheric/climate models have difficulty in reproducing the mei-yu-baiu rainband but have some skills for large-scale circulation (Kawatani and Takahashi 2003; Ninomiya 2009). Similarly, for interannual variability in summer East Asia models display some skills in capturing circulation anomalies but much less so for rainfall (Arai and Kimoto 2008; Chowdary et al. 2010, 2011). Kosaka and Nakamura (2011) showed that climate model biases in mei-yu-baiu rainfall and large-scale lower-tropospheric circulation tend to be linked together in a manner similar to the observed PJ pattern. The adiabatic induction of precipitation anomalies proposed in the present study implies that the midtropospheric horizontal advection of temperature can be used as a measure, at least qualitatively, of the reproducibility of mei-yu-baiu precipitation in numerical models.

Correlation of our SVDs with major modes of SST variability, shown in Table 1, suggests a predictability of summertime mei-yu-baiu precipitation anomalies on one or two seasons lead. The leading covariability mode between precipitation and the midtropospheric temperature advection is significantly correlated with Niño-3.4 SST in the preceding winter and IOBM in the concurrent summer (SVD1 in Table 1), indicative of the Indian Ocean capacitor effect (Yang et al. 2007; Xie et al. 2009). The mode also shows signals of both the PJ and Silk Road patterns in early summer (Figs. 8a,b) and a sole correlation with the PJ pattern in midsummer (Figs. 12a,b). Since the PJ pattern is a primary mediator linking IOBM and East Asia in summer, this difference suggests a tighter connection of mei-yu-baiu rainfall in midsummer than in early summer with ENSO in the preceding winter or IOBM in the concurrent summer. Indeed, correlations between SVD1 and these SST indices are generally higher in midsummer than in early summer (Table 1).

In the mei-yu-baiu rainband, synoptic and mesoscale disturbances are frequently generated and propagate eastward (Ding and Chan 2005; Ninomiya 2000; Ninomiya and Shibagaki 2007). The anomalous circulation and precipitation induced in the upstream region might cause anomalies in the activity and tracks of transient eddies, thereby affecting precipitation anomalies downstream. Whereas the present study examined moisture budgets in relation to transient eddies (Figs. 7 and 11), mechanisms that modulate the transient activity and thereby modify the moisture budget are still unclear. Interaction with transient eddies in interannual variability needs to be investigated in future studies.

Acknowledgments. YK and SPX are supported by the National Science Foundation, NASA, NOAA, and JAMSTEC. HN is supported in part by the Grant-inAid for Scientific Research 22340135 and Innovative 
Area 2205 from the Japanese Ministry of Education, Culture, Sports, Science and Technology (MEXT), and the Global Environment Research Fund (S-5) of the Japanese Ministry of Environment.

\section{REFERENCES}

Arai, M., and M. Kimoto, 2008: Simulated interannual variation in summertime atmospheric circulation associated with the East Asian monsoon. Climate Dyn., 31, 435-447, doi:10.1007/ s00382-007-0317-y.

Chowdary, J. S., S.-P. Xie, J.-Y. Lee, Y. Kosaka, and B. Wang, 2010: Predictability of summer northwest Pacific climate in 11 coupled model hindcasts: Local and remote forcing. J. Geophys. Res., 115, D22121, doi:10.1029/2010JD014595.

- _ - J.-J. Luo, J. Hafner, S. Behera, Y. Masumoto, and T. Yamagata, 2011: Predictability of Northwest Pacific climate during summer and the role of the tropical Indian Ocean. Climate Dyn., 36, 607-621, doi:10.1007/s00382-009-0686-5.

Ding, Q., and B. Wang, 2005: Circumglobal teleconnection in the Northern Hemisphere summer. J. Climate, 18, 3483 3505 .

Ding, Y., and J. C. L. Chan, 2005: The East Asian summer monsoon: An overview. Meteor. Atmos. Phys., 89, 117-142.

Enomoto, T., 2004: Interannual variability of the Bonin high associated with the propagation of Rossby waves along the Asian jet. J. Meteor. Soc. Japan, 82, 1019-1034.

- B. J. Hoskins, and Y. Matsuda, 2003: The formation mechanism of the Bonin high in August. Quart. J. Roy. Meteor. Soc., 129, $157-178$.

Hoskins, B. J., 1980: Representation of the earth topography using spherical harmonics. Mon. Wea. Rev., 108, 111-115.

Hsu, H.-H., and S.-M. Lin, 2007: Asymmetry of the tripole rainfall pattern during the East Asian summer. J. Climate, 20, 4443 4458.

Huang, R., and F. Sun, 1992: Impacts of tropical western Pacific on the East Asian summer monsoon. J. Meteor. Soc. Japan, 70, 243-256.

—, W. Chen, B. Yang, and R. Zhang, 2004: Recent advances in studies of the interaction between the East Asian winter and summer monsoons and ENSO cycle. Adv. Atmos. Sci., 21, 407-424.

Iwao, K., and M. Takahashi, 2008: A precipitation seesaw mode between Northeast Asia and Siberia in summer caused by Rossby waves over the Eurasian continent. J. Climate, 21, 2401-2419.

Kawatani, Y., and M. Takahashi, 2003: Simulation of the Baiu front in a high resolution AGCM. J. Meteor. Soc. Japan, 81, 113-126.

Kodama, Y., 1997: Airmass transformation of the Yamase air flow in the summer of 1993. J. Meteor. Soc. Japan, 75, 737-751.

Kosaka, Y., and H. Nakamura, 2006: Structure and dynamics of the summertime Pacific-Japan teleconnection pattern. Quart. J. Roy. Meteor. Soc., 132, 2009-2030.

$\longrightarrow$, and —, 2010: Mechanisms of meridional teleconnection observed between a summer monsoon system and a subtropical anticyclone. Part I: The Pacific-Japan pattern. J. Climate, 23, 5085-5108.

, and - 2011: Dominant mode of climate variability, intermodel diversity, and projected future changes over the summertime western North Pacific simulated in the CMIP3 models. J. Climate, 24, 3935-3955.
__ _ _ M. Watanabe, and M. Kimoto, 2009: Analysis on the dynamics of a wave-like teleconnection pattern along the summertime Asian jet based on a reanalysis dataset and climate model simulations. J. Meteor. Soc. Japan, 87, 561-580.

Lu, R., and Z. Lin, 2009: Role of subtropical precipitation anomalies in maintaining the summertime meridional teleconnection over the western North Pacific and East Asia. J. Climate, 22, 2058-2072.

Nakamura, H., and T. Fukamachi, 2004: Evolution and dynamics of summertime blocking over the Far East and the associated surface Okhotsk high. Quart. J. Roy. Meteor. Soc., 130, 1213 1233.

Ninomiya, K., 2000: Large- and meso- $\alpha$-scale characteristics of Meiyu/Baiu front associated with intense rainfalls in 1-10 July 1991. J. Meteor. Soc. Japan, 78, 141-157.

_ 2009: Characteristics of precipitation in the Meiyu-Baiu season in the CMIP3 20th century climate simulations. J. Meteor. Soc. Japan, 87, 829-843.

_ Japan in 1951-1980 and large-scale characteristics of wet and dry Baiu. J. Meteor. Soc. Japan, 65, 115-127.

— (Baiu) over Japan. Monsoon Meteorology, Oxford University Press, 93-121.

_ Baiu front and associated precipitation systems. J. Meteor. Soc. Japan, 85B, 103-122.

Nitta, T., 1987: Convective activities in the tropical western Pacific and their impact on the Northern Hemisphere summer circulation. J. Meteor. Soc. Japan, 65, 373-390.

Onogi, K., and Coauthors, 2007: The JRA-25 Reanalysis. J. Meteor. Soc. Japan, 85, 369-432.

Rayner, N. A., D. E. Parker, E. B. Horton, C. K. Folland, L. V. Alexander, D. P. Rowell, E. C. Kent, and A. Kaplan, 2003: Global analyses of sea surface temperature, sea ice, and night marine air temperature since the late nineteenth century. J. Geophys. Res., 108, 4407, doi:10.1029/2002JD002670.

Saji, N. H., B. N. Goswami, P. N. Vinayachandran, and T. Yamagata, 1999: A dipole mode in the tropical Indian Ocean. Nature, 401, 360-363.

Sampe, T., and S.-P. Xie, 2010: Large-scale dynamics of the MeiyuBaiu rainband: Environmental forcing by the westerly jet. J. Climate, 23, 113-134.

Suzuki, S., and B. Hoskins, 2009: The large-scale circulation change at the end of the Baiu season in Japan as seen in ERA40 data. J. Meteor. Soc. Japan, 87, 83-99.

Takaya, K., and H. Nakamura, 2001: A formulation of a phaseindependent wave activity flux for stationary and migratory quasigeostrophic eddies on a zonally varying basic flow. J. Atmos. Sci., 58, 608-627.

Tanaka, M., 1997: Interannual and interdecadal variations of the western North Pacific monsoon and Baiu rainfall and their relationship to the ENSO cycles. J. Meteor. Soc. Japan, $\mathbf{7 5}$, 1109-1123.

Tomita, T., T. Yoshikane, and T. Yasunari, 2004: Biennial and lower-frequency variability observed in the early summer climate in the western North Pacific. J. Climate, 17, 42544266.

Ueda, H., T. Yasunari, and R. Kawamura, 1995: Abrupt seasonal change of large-scale convective activity over the western Pacific in the northern summer. J. Meteor. Soc. Japan, 73, 795-809. 
- M. Ohba, and S.-P. Xie, 2009: Important factors for the development of the Asian-Northwest Pacific summer monsoon. J. Climate, 22, 649-669.

Wang, B., R. Wu, and K.-M. Lau, 2001: Interannual variability of the Asian summer monsoon: Contrasts between the Indian and the western North Pacific-East Asian monsoons. J. Climate, 14, 4073-4090.

Wang, Y., 1992: Effects of blocking anticyclones in Eurasia in the rainy season (Meiyu/Baiu season). J. Meteor. Soc. Japan, 70, 929-951.

Xie, P., and P. A. Arkin, 1997: Global precipitation: A 17-year monthly analysis based on gauge observations, satellite estimates and numerical model outputs. Bull. Amer. Meteor. Soc., 78, 2539-2558.
Xie, S.-P., K. Hu, J. Hafner, H. Tokinaga, Y. Du, G. Huang, and T. Sampe, 2009: Indian Ocean capacitor effect on Indo-Western Pacific climate during the summer following El Niño. J. Climate, 22, 730-747.

Yamaura, T., and T. Tomita, 2011: Spatiotemporal differences in the interannual variability of Baiu frontal activity in June. Int. J. Climatol., 31, 57-71, doi:10.1002/joc.2058.

Yang, J., Q. Liu, S.-P. Xie, Z. Liu, and L. Wu, 2007: Impact of the Indian Ocean SST basin mode on the Asian summer monsoon. Geophys. Res. Lett., 34, L02708, doi:10.1029/2006GL028571.

Yasui, S., and M. Watanabe, 2010: Forcing processes of the summertime circumglobal teleconnection pattern in a dry AGCM. J. Climate, 23, 2093-2114. 